\title{
A CARTILHA COMO INSTRUMENTO DE APOIO DIDÁTICO: UMA ABORDAGEM SOBRE OS INVERTEBRADOS DA CAATINGA
}

\author{
Geraldo Miranda do Nascimento ${ }^{1}$ \\ Thiago Braz Barbosa de Sousa ${ }^{2}$ \\ Xavier Arnan ${ }^{3}$ \\ Elâine Maria dos Santos Ribeiro ${ }^{4}$ \\ Regina Lúcia Félix de Aguiar Lima ${ }^{5}$
}

Resumo: Apesar da sua importância ecológica, os animais invertebrados são pouco apreciados pelas pessoas. Nas escolas, há uma lacuna na disseminação de informações relativas a esse grupo, principalmente quando se trata de invertebrados de ecossistemas pouco estudados, como é o caso da Caatinga. Assim, torna-se necessária a utilização de ferramentas paradidáticas para contemplar esses conteúdos, e desenvolver reflexões e empatia por parte dos estudantes para com esse grupo animal. Este trabalho teve como objetivo construir uma cartilha para divulgação do conhecimento científico sobre invertebrados da Caatinga, a qual será útil como material de apoio para professores no ensino de ciências.

Palavras-chave: Ensino de Ciências; Educação Ambiental; Ensino Fundamental; Ferramenta Paradidática.

Abstract: Despite their ecological importance, invertebrate animals have been little appreciated by people. In schools, there is a gap in the dissemination of information about this group, especially when it comes to invertebrates from poorly studied ecosystems, such as the Caatinga. Thus, it becomes necessary to use paradidactic tools to contemplate these contents, and to develop reflections and empathy on the part of the students towards this animal group. This work aimed to build a booklet for the dissemination of scientific knowledge about Caatinga invertebrates, which will be useful as support material for teachers in science teaching.

Keywords: Science Teaching; Environmental Education; Elementary School; Paradidactic Tool.

\footnotetext{
${ }^{1}$ Universidade de Pernambuco. E-mail: geraldo.nascimento@upe.br. http://lattes.cnpq.br/7355516007328154

2Universidade de Pernambuco. E-mail: thiago.braz@upe.br. http://lattes.cnpq.br/0813482482466479

${ }^{3}$ Universidade de Pernambuco. E-mail: xavier.arnan@upe.br. http://lattes.cnpq.br/0204772340851287

${ }^{4}$ Universidade de Pernambuco, E-mail: elaine.ribeiro@upe.br. http://lattes.cnpq.br/3304685448889789

5Universidade de Pernambuco, E-mail: regina.aguiar@upe.br. http://lattes.cnpq.br/8549101690272163
} 


\section{Introdução}

Quando entendemos a percepção humana sobre determinada situação, torna-se possível contribuir significativamente para a resolução de questões ambientais e sociais (PEDRINI et al. 2013). A maneira como as pessoas percebem o ambiente pode nos dizer muito a respeito de sua visão de mundo, sensações, valores e opiniões (SILVA; ALBUQUERQUE, 2018), uma vez que esse conjunto de variáveis são produtos das percepções, e podem ser moldadas através das experiências e conhecimentos culturalmente construídos (PROFICE, 2018).

Estudos com a percepção ambiental de diversos grupos têm sido realizados, e há indícios de aversão a determinados ambientes e espécies animais menos carismáticas (SILVA et al. 2018). A escola tem se mostrado um ambiente propício para reflexão e construção de novos conhecimentos e percepções a respeito do ambiente (SILVA et al., 2010), além de proporcionar experiências positivas através do ensino a respeito de grupos animais, comumente temidos pelas crianças, contribuindo para o desenvolvimento da biofilia (BURGESS; MAYER-SMITH, 2011).

A literatura tem mostrado que estudantes expressam sentimentos negativos para animais invertebrados e que muitos desconhecem a importância ecológica que esses animais têm para o funcionamento e a manutenção dos ecossistemas (MODRO et al. 2009; TRINDADE; SILVA JÚNIOR; TEIXEIRA, 2012). Isso é especialmente preocupante porque a escola e os livros didáticos também têm contribuído para essa percepção negativa ao abordar essas espécies sob uma visão antropocentrista (TRINDADE; SILVA JÚNIOR; TEIXEIRA, 2012).

Não obstante, o semiárido e a Caatinga, seu principal ecossistema, são pouco explorados no currículo escolar; outros ecossistemas acabam sendo mais abordados pelos professores e até pelos livros didáticos, distanciando 0 estudante da sua realidade e do seu contexto ambiental regional (TRIGUEIRO, 2017). Tendo em vista que a Caatinga é um ecossistema brasileiro que, por muito tempo, esteve associado à ideia de improdutividade e pobreza em biodiversidade, estudos recentes têm mostrado que há um grande número de espécies endêmicas nesta região (SILVA; LEAL; TABARELLI, 2017). Essa diversidade de espécies já catalogadas pode ser explicada pelas adaptações a diferentes filtros ambientais que atuam sobre esse ecossistema.

Há um grande número de espécies já identificadas como exclusivas da Caatinga (VICENTE, 2020). Dessas, há espécies de abelhas já bem conhecidas (SILVA; LEAL; TABARELLI, 2017), que, assim como outros invertebrados, desempenham funções fundamentais para o funcionamento desse ecossistema. Entretanto, essas espécies ainda não receberam a devida atenção e importância, o que é reflexo da pouca atenção que a Caatinga tem quando comparada com outros ecossistemas brasileiros.

Portanto, sendo este um dos ecossistemas mais ameaçados e fragilizados do Brasil, é de extrema importância desenvolver atividades que Revbea, São Paulo, V. 15, № 6: 17-51, 2020. 
visem valorizar a fauna, e especialmente de um grupo já pouco valorizado em geral, mas com uma relevância ecológica imensa, como são os invertebrados.

Essas problemáticas reforçam o desconhecimento da ecologia desses animais e perpetuam sentimentos negativos e de aversão. Assim, considerando que os conhecimentos das crianças podem ser influenciados pela educação escolar (BARRAZA; CUARÓN, 2004), a realização de atividades contextualizadas, utilizando a Educação Ambiental como ferramenta para o ensino de Ciências, pode contribuir na construção de conhecimentos e valorização também dos invertebrados da Caatinga.

Nesse contexto, é necessário repensar o ensino de Ciências contextualizado, para melhor valorizar a fauna de animais invertebrados. Portanto, o uso de diferentes recursos didáticos e paradidáticos tem sido indicado como ferramentas fundamentais no processo de aprendizagem do aluno, especialmente no ensino de Ciências que, por ser uma área multidisciplinar, dispõe de uma gama desses recursos (VIEIRA; BIANCONI; DIAS, 2005). Desse modo, este estudo teve como objetivo a construção e disponibilização de uma cartilha educativa contextualizada na fauna de invertebrados da Caatinga, como estratégia educacional para auxiliar nas atividades realizadas em sala de aula por professores de Ciências do Ensino Fundamental.

\section{Uso de cartilhas como materiais paradidáticos para complementar abordagem de temas regionais}

Sabe-se que o grupo de animais invertebrados é o mais abundante nos ecossistemas e que muitas espécies desempenham serviços ecossistêmicos essenciais para a manutenção da vida humana (BLACK; SHEPARD; ALLEN, 2001). No entanto, conhecimentos sobre a biologia desses animais e sua importância para o funcionamento dos ecossistemas parecem não ser bem disseminados nas escolas. O ensino sobre os invertebrados, muitas vezes, baseia- se sob uma perspectiva antropocêntrica, reforçado por uma concepção utilitarista onde os animais pertencentes a este grupo são apresentados como os que podem ser úteis ou nocivos ao ser humano (ESTEVE; JAÉN; BANOSGONZÁLEZ, 2019).

Assim, em sala de aula, um dos obstáculos para a disseminação de conhecimentos a respeito da diversidade faunística tem sido a acomodação docente em avaliar criticamente o livro didático e buscar fontes adicionais de pesquisas, se necessário. Alguns estudos indicam que o livro didático utilizado no ensino de Ciências possui abordagem limitada, e às vezes inexistente, a respeito de espécies nativas da Caatinga e do Cerrado (BARBOSA; RAMOS, 2020; DINIZ; CORDEIRO JÚNIOR; SABINO, 2016). Tratando-se do grupo dos invertebrados, essa situação torna-se ainda mais comum, e o desconhecimento da biologia dos invertebrados pode contribuir para que sentimentos de aversão e apatia sejam perpetuados, tendo implicações diretas na conservação dessas espécies (LEANDRO; JAY-ROBERT, 2019). Alguns trabalhos têm mostrado 
que crianças e adolescentes tendem a conhecer mais animais vertebrados (DRISSNER; MUNZ, 2019; LEANDRO; JAY-ROBERT, 2019); portanto, tornase necessário buscar meios para desenvolver estratégias e metodologias de ensino que trazem ao conhecimento dos estudantes os animais invertebrados.

Nesse sentido, a Educação Ambiental (EA) surge como um instrumento de valorização da biodiversidade, além de trazer abordagens de conservação, preservação e uso sustentável dos recursos naturais, buscando despertar nos indivíduos a sensibilização para as questões pró-ambiente. Conhecida como Lei da Educação Ambiental, a Lei no 9.795/99 define EA como os processos que levam o indivíduo e a coletividade a construir valores sociais, conhecimentos, habilidades, atitudes e competências voltadas para a conservação do ambiente e seu uso sustentável (BRASIL, 1999). Entretanto, para que esses processos sejam efetivos, é necessário voltar-se ao público que se pretende trabalhar, desenvolvendo uma linguagem adequada, interpretativa e de fácil compreensão, e que o problema abordado faça parte da realidade das pessoas. E para tanto, ferramentas como guias e cartilhas ambientais tornam-se excelentes opções (PACIENCIA et al., 2015).

A cartilha é um recurso pedagógico que reúne informações, jogos e imagens, baseado na diversão para articular o processo de ensinoaprendizagem, a qual é definida por Bacelar et al. (2009) como "qualquer compilação elementar que preceitua um padrão de comportamento por meio de ilustrações". A utilização desse recurso segue, inclusive, as orientações das Diretrizes Curriculares Nacionais para a formação de professores da educação básica, e também dos Parâmetros Curriculares Nacionais, que sugerem o uso de artifícios e ferramentas de apoio que possam inovar o processo de ensinoaprendizagem (BRASIL, 2002).

A utilização de cartilhas tem sido cada vez mais comum nos espaços formais e informais de educação (ALVES et al. 2019; BACELAR et al., 2009; SMA, 2003), com aplicação na divulgação do conhecimento científico, promovendo a popularização da Ciência (ALVES et al. 2019). No estado de São Paulo, muitos professores se reuniram e desenvolveram, com apoio da Secretaria do Meio Ambiente de São Paulo, uma cartilha que tratou de temas relacionados ao meio ambiente e sua conservação, a qual foi produzida em larga escala e distribuída a mais de 400 mil estudantes da rede de ensino do estado (SÃO PAULO, 2003).

Portanto, alguns trabalhos têm buscado apresentar alternativas de apoio à disseminação de conteúdo científico a respeito da biodiversidade regional, buscando melhorar o conhecimento e valorização a respeito da mesma. No semiárido nordestino, Carvalho et al. (2020) realizaram atividades lúdicas, voltadas ao conhecimento e valorização da biodiversidade da Caatinga, com estudantes, a fim de apresentar serviços ecossistêmicos propiciados pelas formigas e desconstruir a imagem negativa que os estudantes tinham desses animais. Essas atividades tiveram resultados positivos, e foram discutidas também com a população local, tornando- se uma 
forma de disseminar informações científicas de maneira lúdica e compreensível fora do mundo acadêmico.

A utilização de cartilhas contextualizadas com informações de espécies que ocorrem na Caatinga pode contribuir significativamente na ampliação de conhecimentos a respeito da biodiversidade, e abordar conteúdos que o livro didático não contempla de maneira suficiente (DINIZ; CORDEIRO JÚNIOR; SABINO, 2016). Algumas análises têm mostrado que o livro didático possui limitações quanto à aproximação da realidade dos estudantes. Na zona rural do agreste de Pernambuco, Barbosa e Ramos (2020) observaram que o livro didático utilizado pelo professor de Ciências não era uma ferramenta suficiente para abordagens a respeito da biodiversidade da Caatinga. Os autores concluem que mesmo que os estudantes do $6^{\circ}$ e $7^{\circ}$ ano do Ensino Fundamental já possuam conhecimentos prévios a respeito de elementos da fauna, flora e socioculturais locais, para que o professor conseguisse abordar esse tipo de conhecimento, era necessário recorrer a meios externos.

Assim, a construção e utilização de materiais paradidáticos como complementação para conteúdo que envolvem a fauna de invertebrados e sua importância, é ainda uma ação necessária e se mostra uma alternativa plausível, uma vez que é um conteúdo pouco explorado durante as aulas. E a disponibilização ampla desse material para os professores torna-se importante, uma vez que os trabalhos que buscam a produção de cartilhas com invertebrados estão, geralmente, limitados a trabalhos de conclusão de curso, como as monografias, e estão direcionados a medidas de prevenção a doenças parasitoides transmitidas através de mosquitos vetores, por exemplo.

\section{Metodologia}

Para a primeira fase de desenvolvimento da cartilha sobre invertebrados da Caatinga, foi realizada uma pesquisa bibliográfica em sites, artigos e outros meios de informação sobre o tema para identificar algumas espécies de invertebrados, além de consultar especialistas da área em busca de informações sobre a biologia e ecologia dessas espécies. Os sites utilizados na pesquisa foram: EureKa Brasil (http://eurekabrasil.com/); Toda Matéria (https://www.todamateria.com.br/); $\quad$ Toda Biologia (https://www.todabiologia.com); Portal UFLA (https://ufla.br/); Ministério do Meio Ambiente (https://www.mma.gov.br).

O público alvo deste trabalho são os alunos do Ensino Fundamental, especificamente os alunos do $6^{\circ}$ e $7^{\circ}$ ano. As duas turmas foram escolhidas por possuírem afinidade com a proposta da cartilha; o currículo do 6ํa ano tem, no eixo temático Vida e Ambiente, assuntos relacionados às características do seres vivos aquáticos e terrestres e a conservação do meio ambiente, enquanto o currículo do $7^{\circ}$ ano aborda questões ligadas à Ecologia, fatores bióticos e abióticos, entre outros (PERNAMBUCO, 2013)

A composição da cartilha consistiu na apresentação das espécies por meio de atividades lúdicas, como caça-palavras, labirintos, palavras-cruzadas,

revista brasileira educação ambiental 
ilustrações, imagens e textos informativos com curiosidades, a fim de estimular os estudantes a conhecerem as espécies, sua importância e seus serviços ecossistêmicos prestados. O material foi elaborado com linguagem simples e de fácil compreensão, adequado ao nível de desenvolvimento cognitivo dos estudantes, e poderá servir de apoio para as aulas de Ciências a respeito do meio ambiente e sua biodiversidade.

\section{Resultados e discussão}

A análise de trabalhos científicos e guias informativos a respeito das espécies de invertebrados da Caatinga possibilitou listar e selecionar espécies típicas do ecossistema (Tabela 1) para composição da cartilha, sendo a maioria pertencente ao filo Arthropoda.

A cartilha aqui apresentada foi pensada como um instrumento, que pode ser utilizado pelos professores durante as aulas para valorizar o ecossistema Caatinga e sua fauna de invertebrados, tendo em vista a necessidade desses materiais para esse tema. Entretanto, não foi possível testar sua aplicação e, por esse motivo, sua efetividade será discutida utilizando trabalhos que tiveram metodologias semelhantes e as quais estão aqui descritas.

A cartilha poderá ser utilizada antes, ou após uma aula sobre a Caatinga. No primeiro caso, servirá de estímulo para os estudantes pesquisarem antes da aula, e construírem ou ampliarem conhecimentos prévios sobre a temática que será abordada na aula. No segundo caso, se a aplicação ocorrer após a aula, o material irá servir para fixação da aprendizagem, sendo necessário ao professor seguir um roteiro de aula que se assemelhe ao conteúdo da cartilha, podendo deixar algumas lacunas a serem preenchidas com a consulta ao material, leitura e resolução das atividades contidas nele.

Embora algumas das espécies incluídas na lista ocorram também em outros ecossistemas e regiões fitogeográficas, em relação a outras espécies de invertebrados, possivelmente com a mesma relevância ecológica, essas foram selecionadas por: 1) serem espécies com taxonomia bem definida; 2) desempenharem serviços ecossistêmicos essenciais; 3) apresentarem distribuição ampla dentro da área da Caatinga; 4) serem representativas quanto aos principais grupos de invertebrados da Caatinga; e/ou 5) apresentarem curiosidades. Portanto, essas são espécies que podem instigar as pessoas a desenvolverem empatia pelos invertebrados, que, até hoje, foram muito negligenciados. 
Tabela 1: Lista de espécies de invertebrados representativas do ecossistema Caatinga

\begin{tabular}{|c|c|c|c|}
\hline \multicolumn{4}{|c|}{ INVERTEBRADOS DA CAATINGA } \\
\hline FILO & FAMÍLIA & ESPÉCIE/AUTOR & NOME POPULAR \\
\hline Annelida & Glossoscolecidae & $\begin{array}{l}\text { Pontoscolex corethrurus } \\
\text { (Müller, 1857) }\end{array}$ & Minhoca-mansa \\
\hline Arthropoda & Araneidae & $\begin{array}{l}\text { Argiope argentata } \\
\text { (Fabricius, 1775) }\end{array}$ & Aranha-de-prata \\
\hline Arthropoda & Theraphosidae & $\begin{array}{l}\text { Acanthoscurria natalensis } \\
\text { (Chamberlin, 1917) }\end{array}$ & $\begin{array}{l}\text { Aranha caranguejeira ou } \\
\text { tarântula }\end{array}$ \\
\hline Arthropoda & Buthidae & $\begin{array}{l}\text { Tityus stigmurus } \\
\text { (Thorell, 1876) }\end{array}$ & Escorpião-do-nordeste \\
\hline Arthropoda & Scarabaeidae & $\begin{array}{l}\text { Digitonthophagus gazella } \\
\text { (Fabricius 1787) }\end{array}$ & Besouro rola-bosta \\
\hline Arthropoda & Formicidae & $\begin{array}{l}\text { Dinoponera quadriceps } \\
\text { (Santschi, 1921) }\end{array}$ & $\begin{array}{l}\text { Formiga gigante da } \\
\text { Caatinga }\end{array}$ \\
\hline Arthropoda & Formicidae & $\begin{array}{l}\text { Atta opaciceps } \\
\text { (Borgmeier, 1939) }\end{array}$ & Saúva-do-sertão \\
\hline Arthropoda & Apidae & $\begin{array}{l}\text { Melipona mandacaia } \\
\text { (Smith, 1863) }\end{array}$ & Mandaçaia \\
\hline Arthropoda & Apidae & $\begin{array}{l}\text { Frieseomelitta doederleini } \\
\text { (Friese, 1900) }\end{array}$ & Abelha branca \\
\hline Arthropoda & Nymphalidae & $\begin{array}{l}\text { Fountainea halice moretta } \\
\text { (H. Druce, 1877) }\end{array}$ & Borboleta (nome genérico) \\
\hline Arthropoda & Nymphalidae & $\begin{array}{l}\text { Hypna clymnestra forbesi } \\
\text { (Godman \& Salvin, 1884) }\end{array}$ & Borboleta (nome genérico) \\
\hline
\end{tabular}

Fonte: Autoria própria.

A cartilha desenvolvida traz informações a respeito das características desses invertebrados, suas funções ecológicas, seu nicho e curiosidades apresentadas por dois personagens ilustrados (Figura 1). Além disso, conta com imagens, para uma melhor visualização das espécies e reconhecimento por parte dos estudantes.

O arquivo da cartilha está disponível para download, no formato digital, no link (http://w2.portais.atrio.scire.net.br/upe-peppgctas/index.php/pt/downloads/viewdownload/4-formularios/46-cartilhainvertebrados-da-caatinga). 


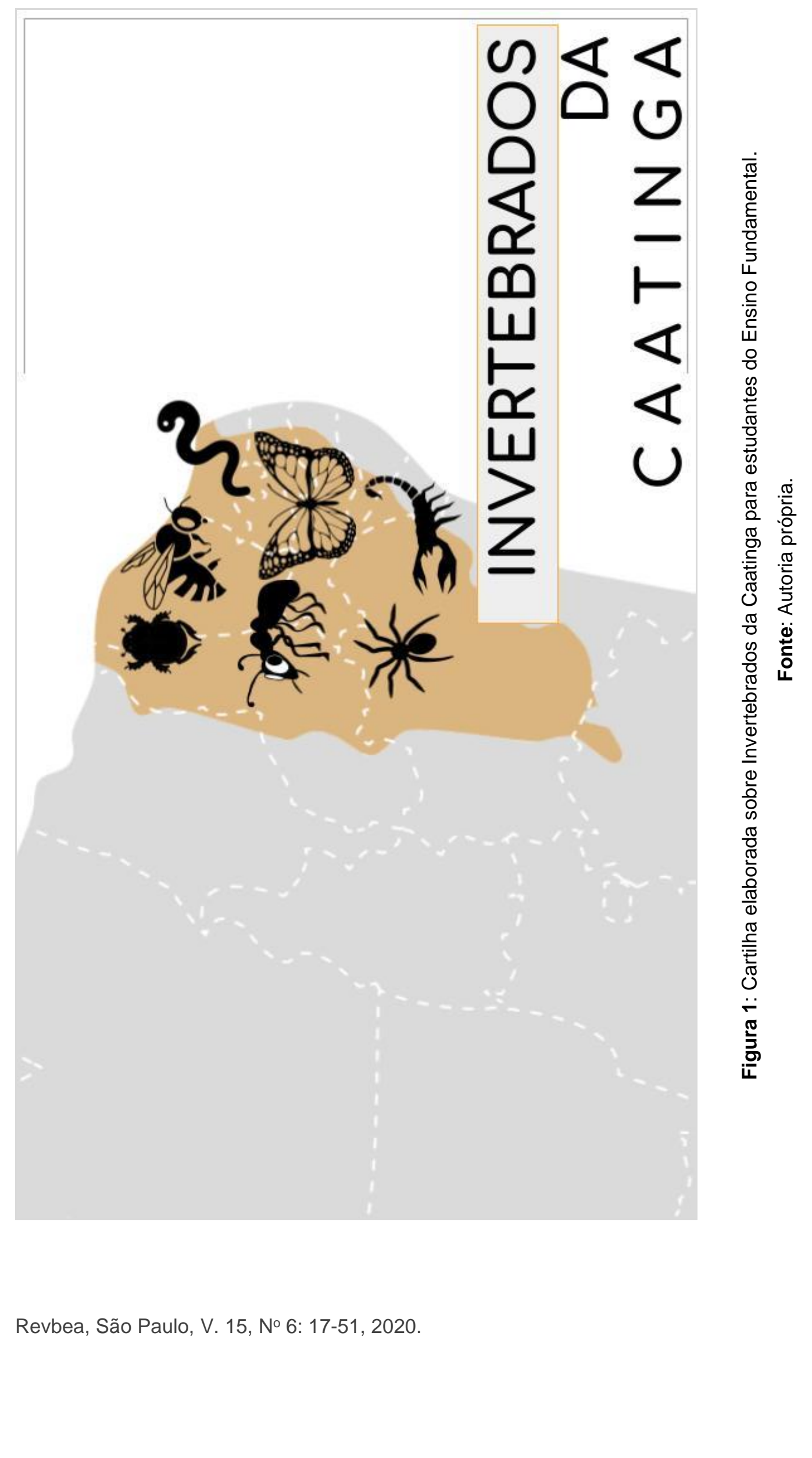



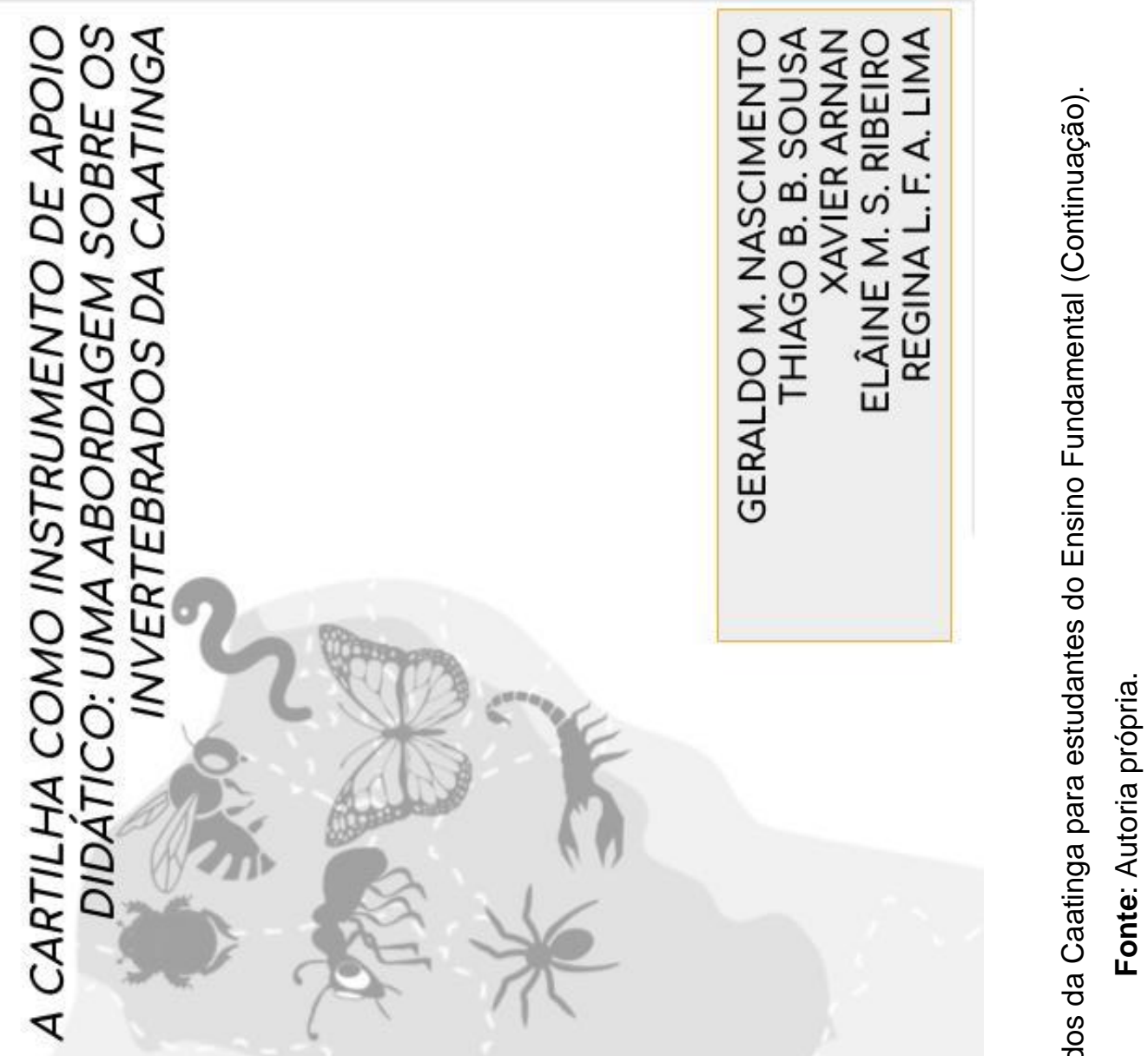

revista brasileira educação

Revbea, São Paulo, V. 15, № 6: 17-51, 2020. ambiental 


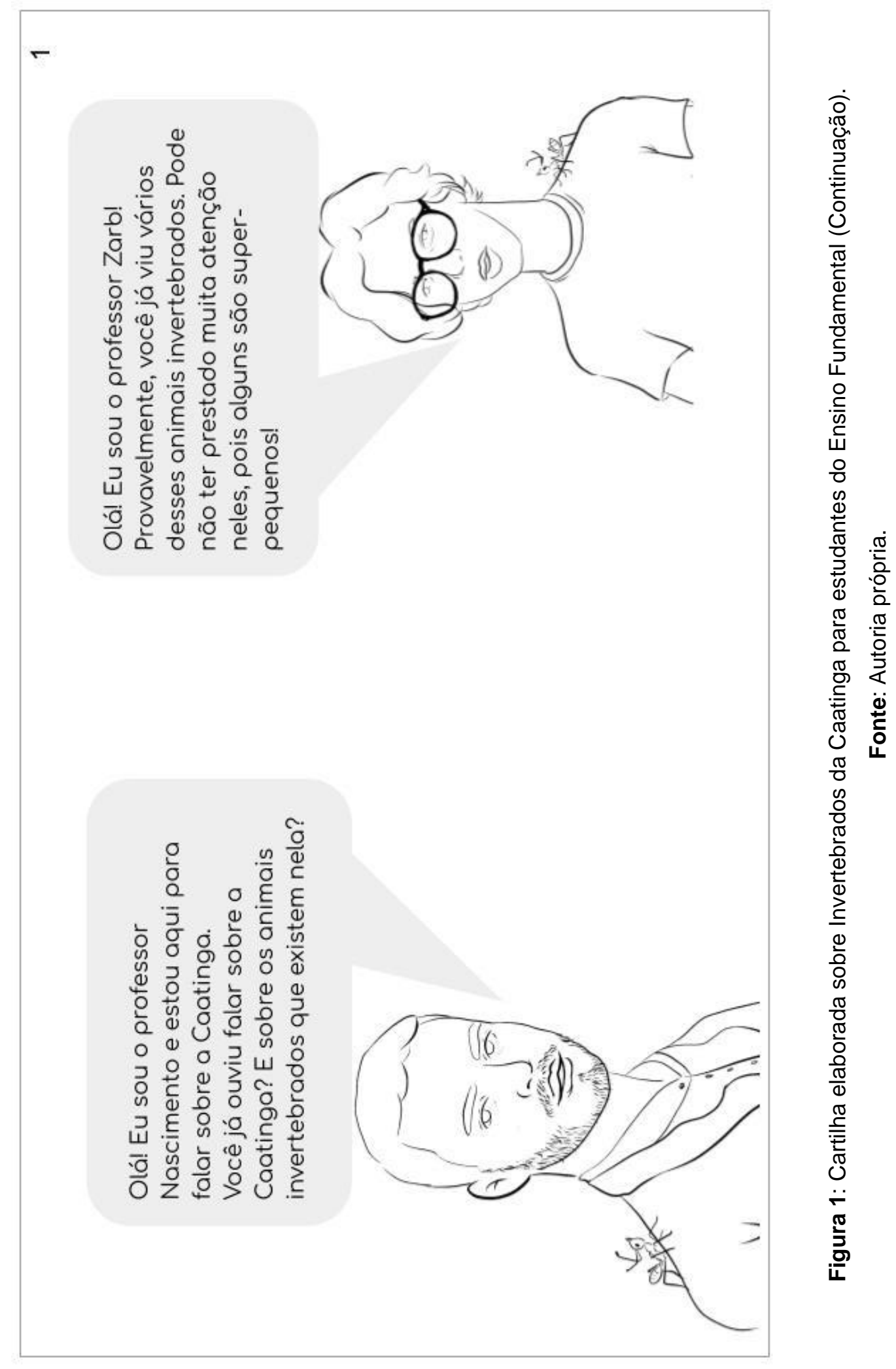




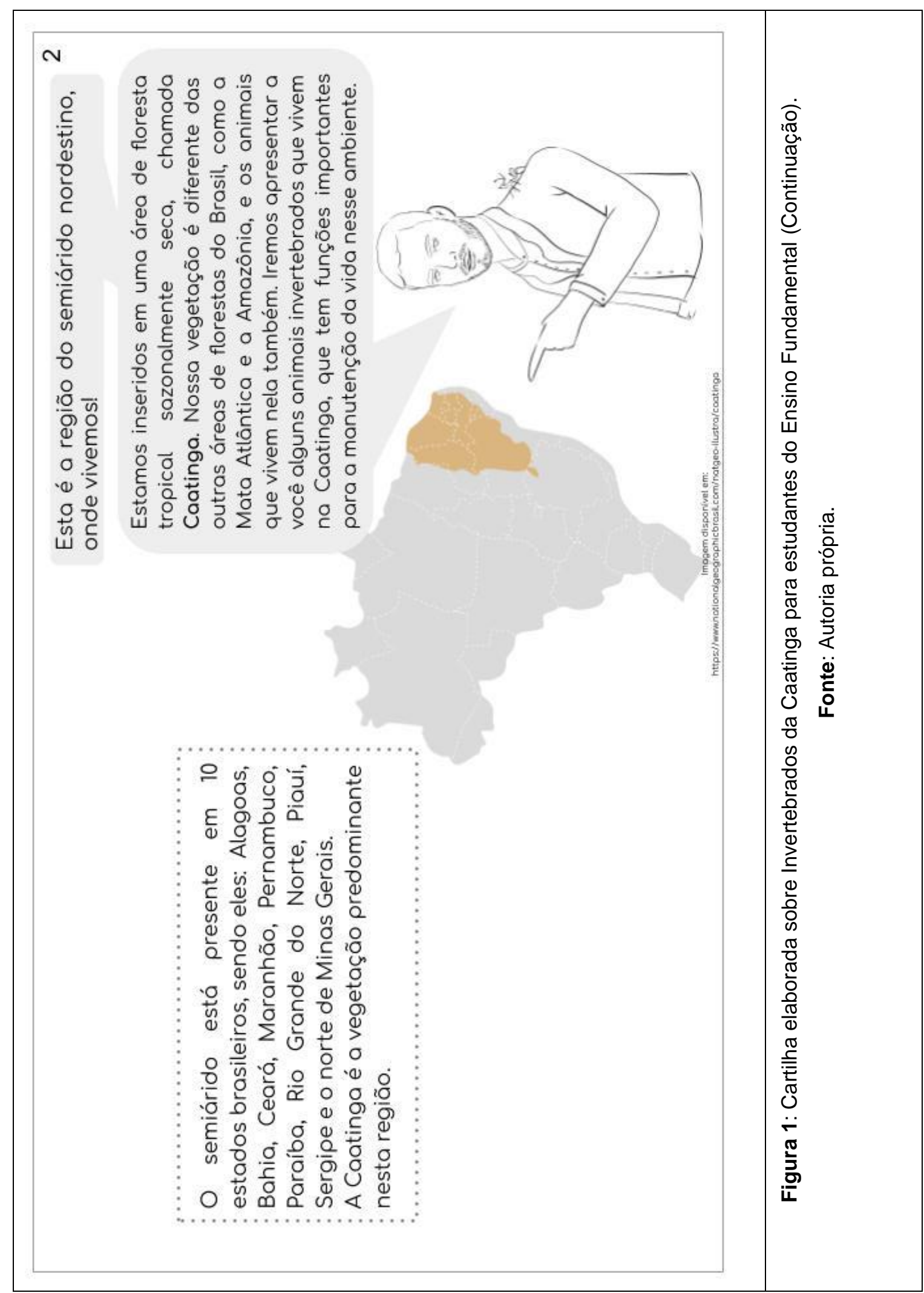

Revbea, São Paulo, V. 15, № 6: 17-51, 2020. revista brasileira educação ambiental 


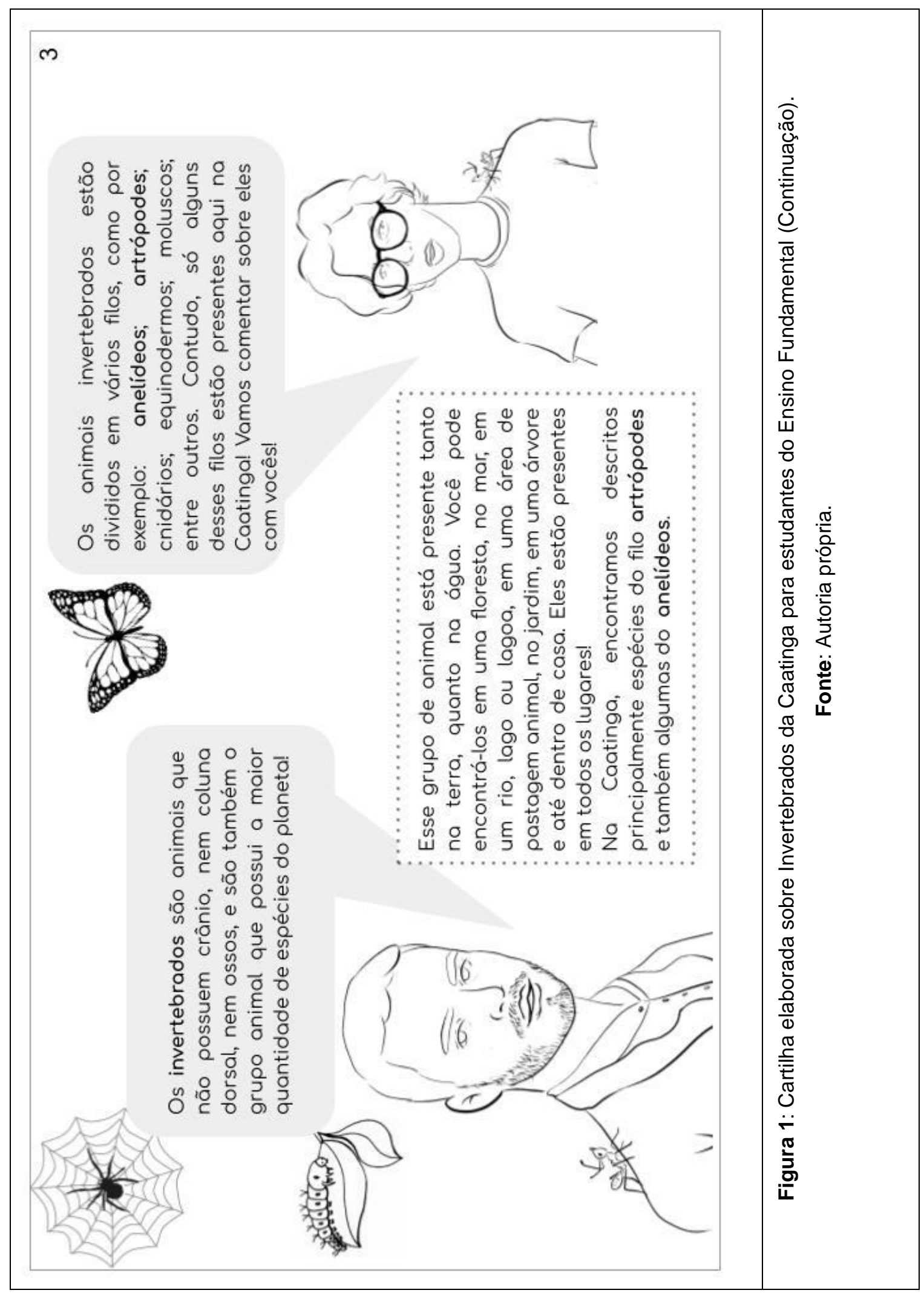

Revbea, São Paulo, V. 15, № 6: 17-51, 2020. 


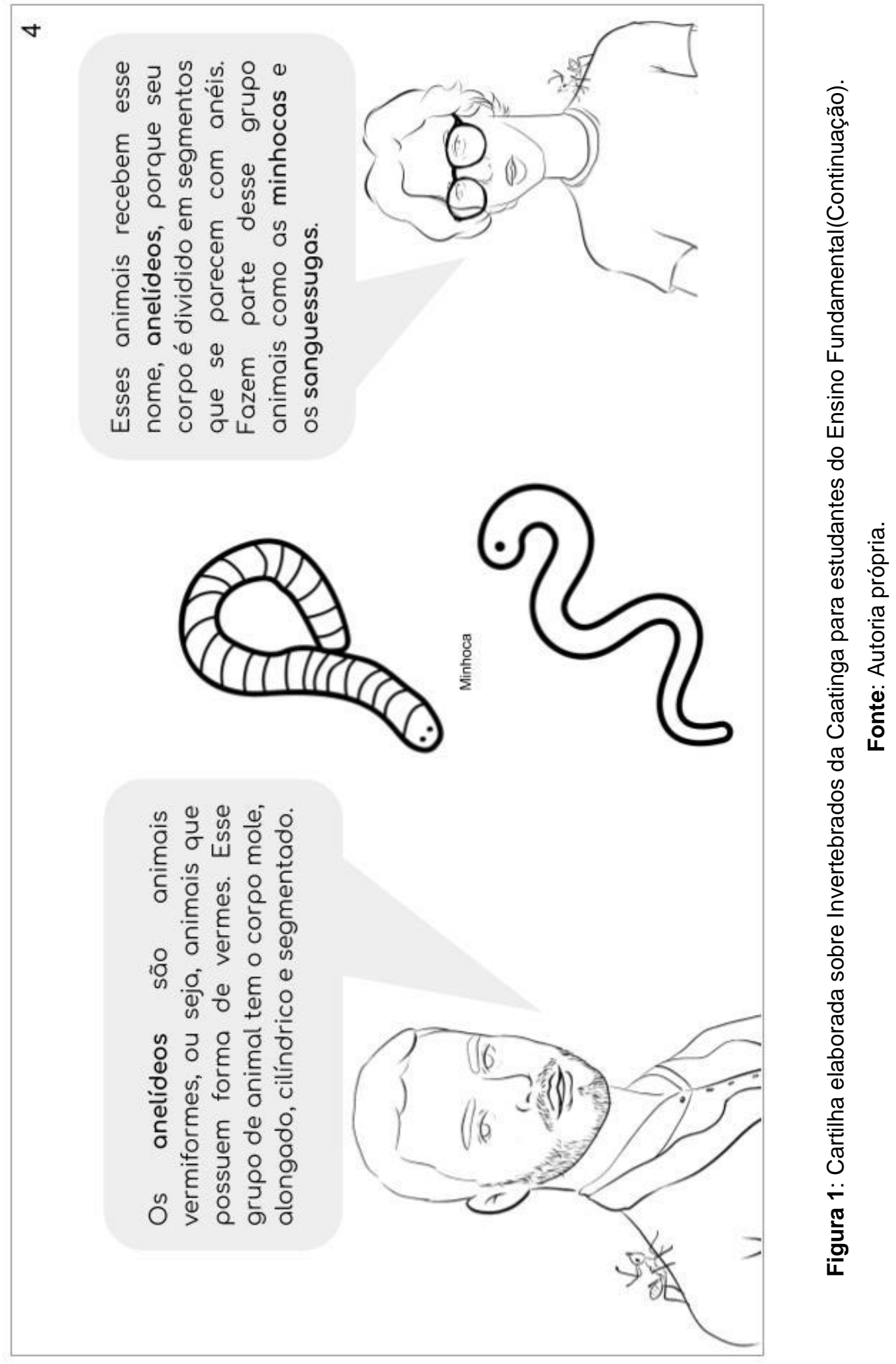

Revbea, São Paulo, V. 15, № 6: 17-51, 2020. 


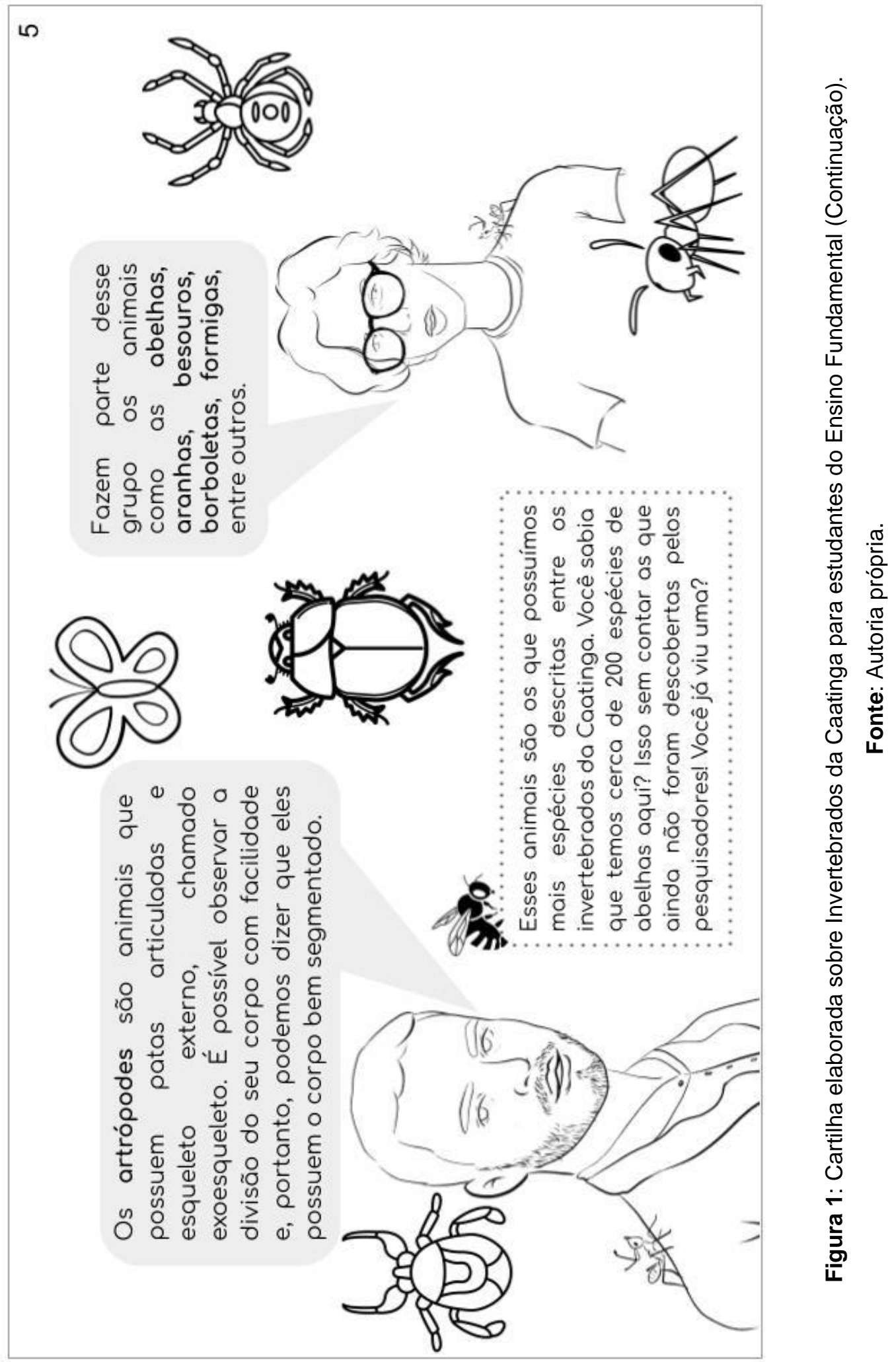




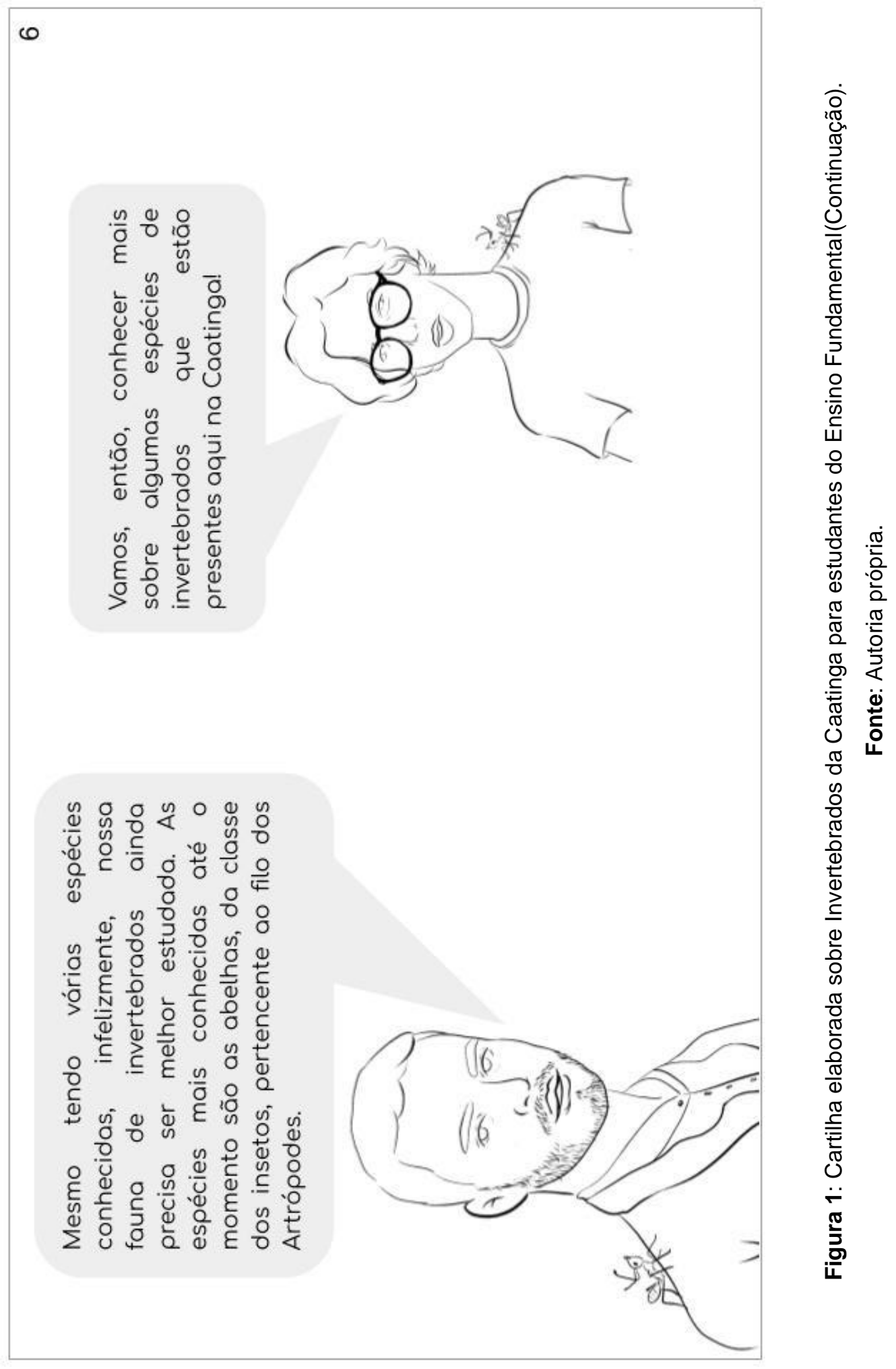

Revbea, São Paulo, V. 15, № 6: 17-51, 2020.

revista brasileira educação ambiental 


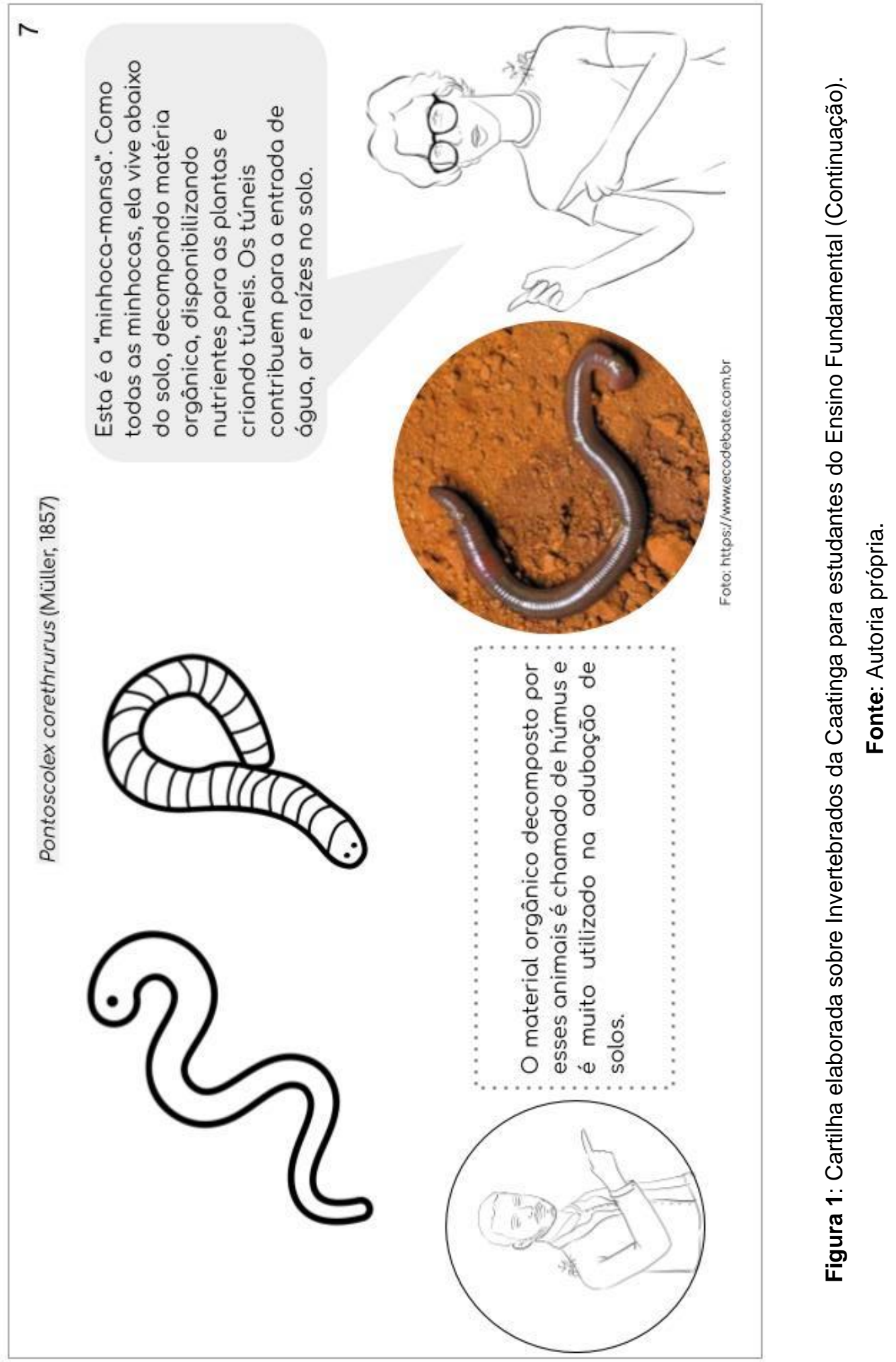



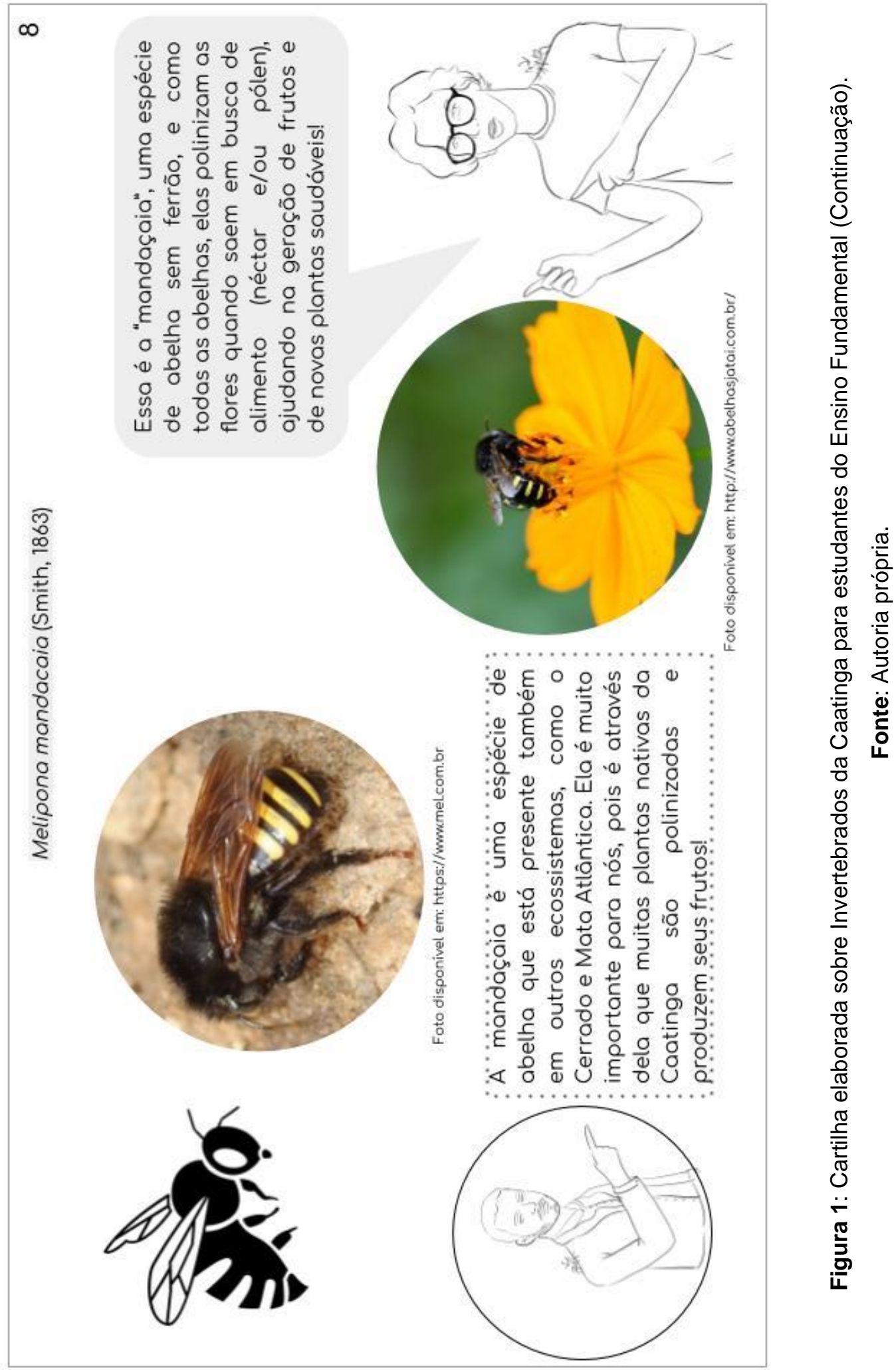

Revbea, São Paulo, V. 15, № 6: 17-51, 2020. 

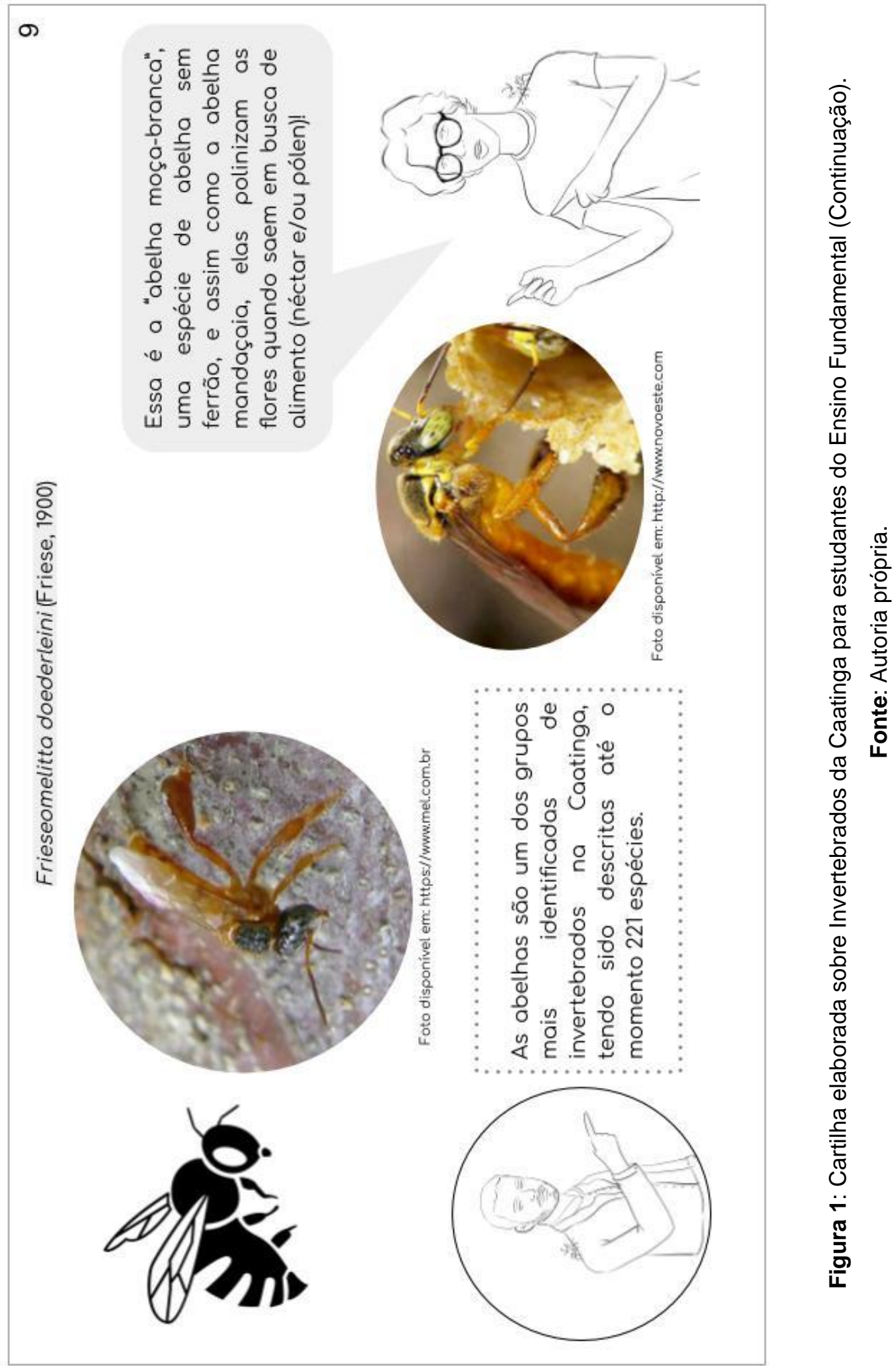

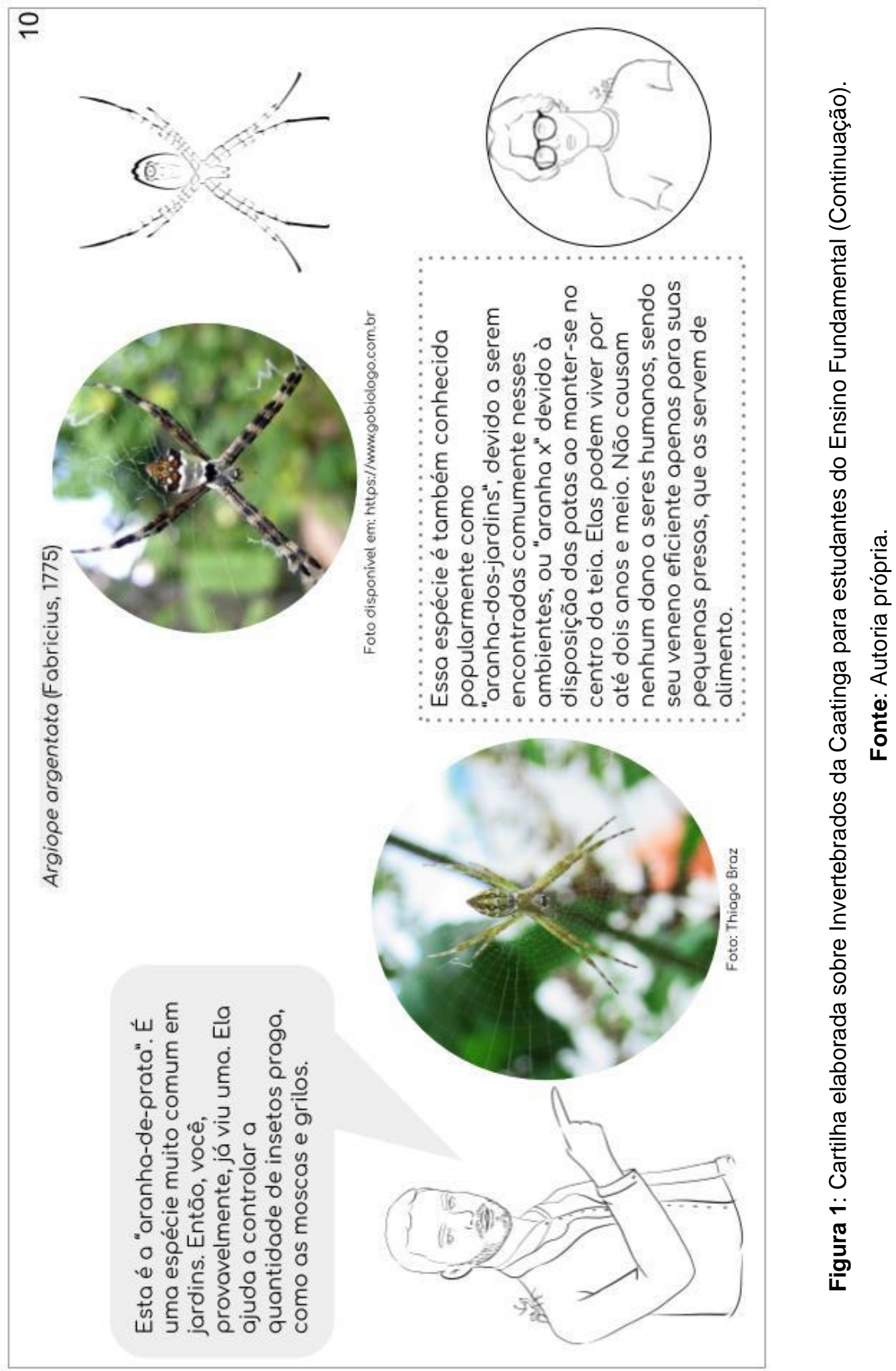

Revbea, São Paulo, V. 15, № 6: 17-51, 2020. 


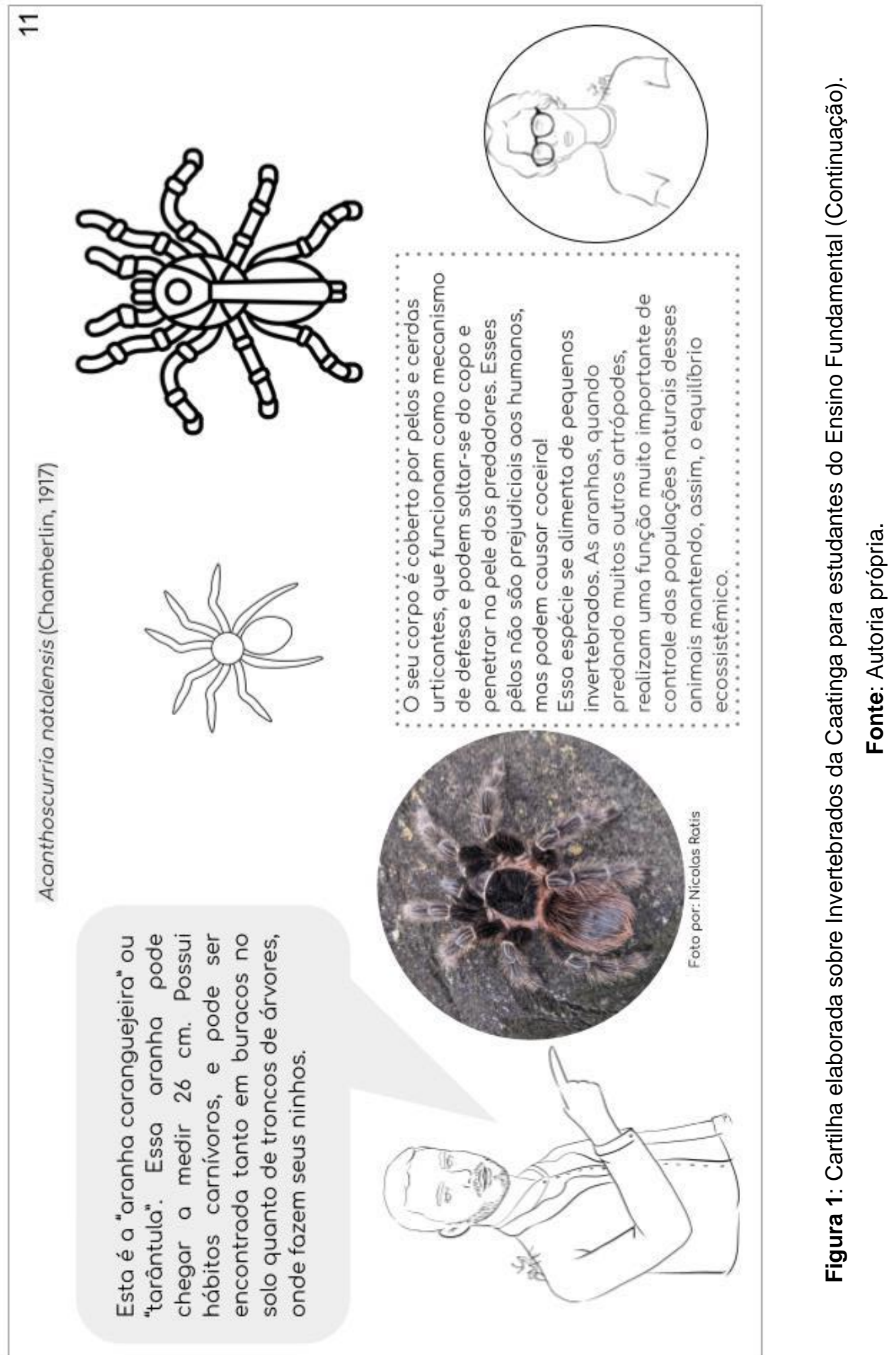



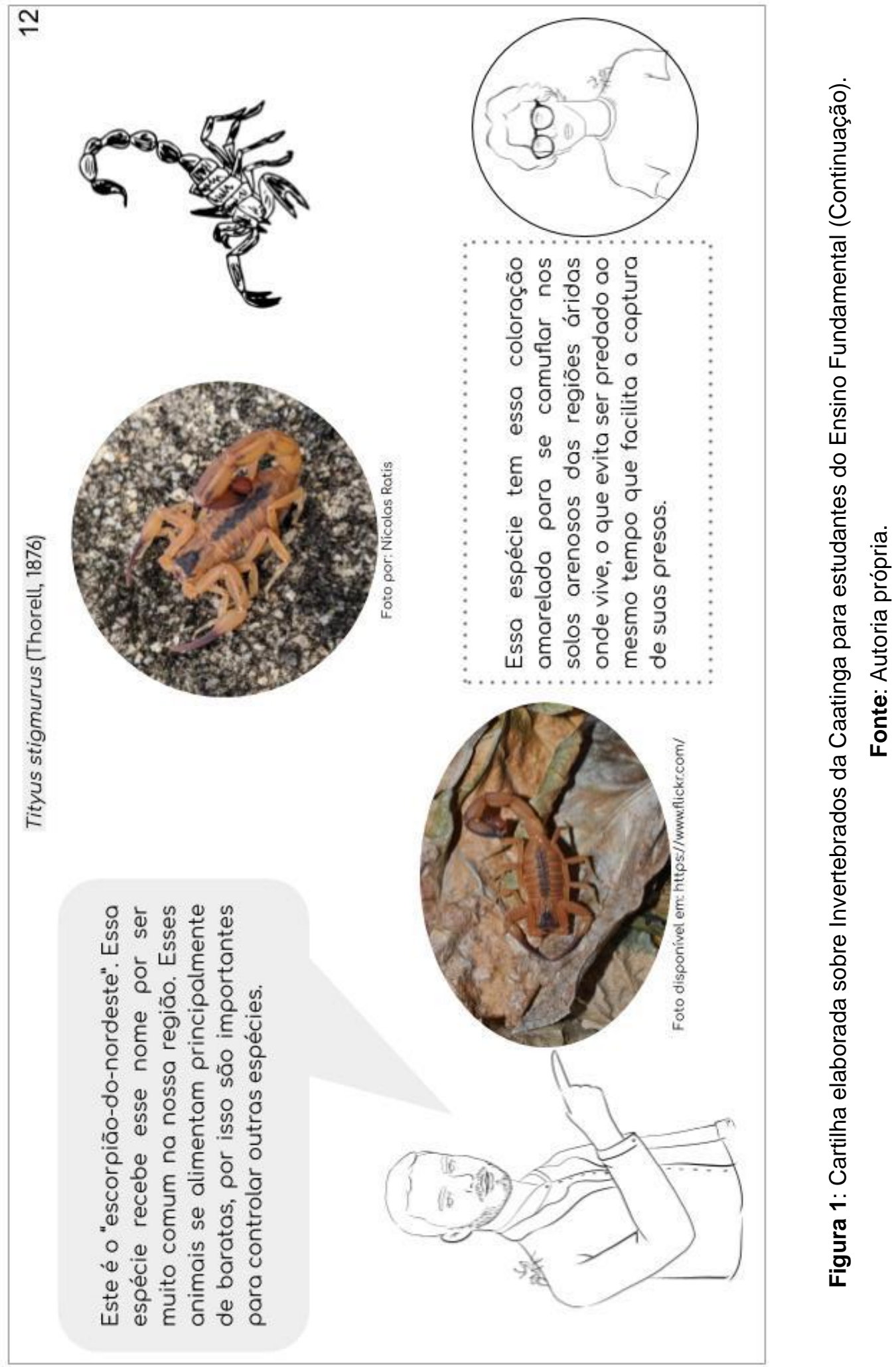

Revbea, São Paulo, V. 15, № 6: 17-51, 2020. 

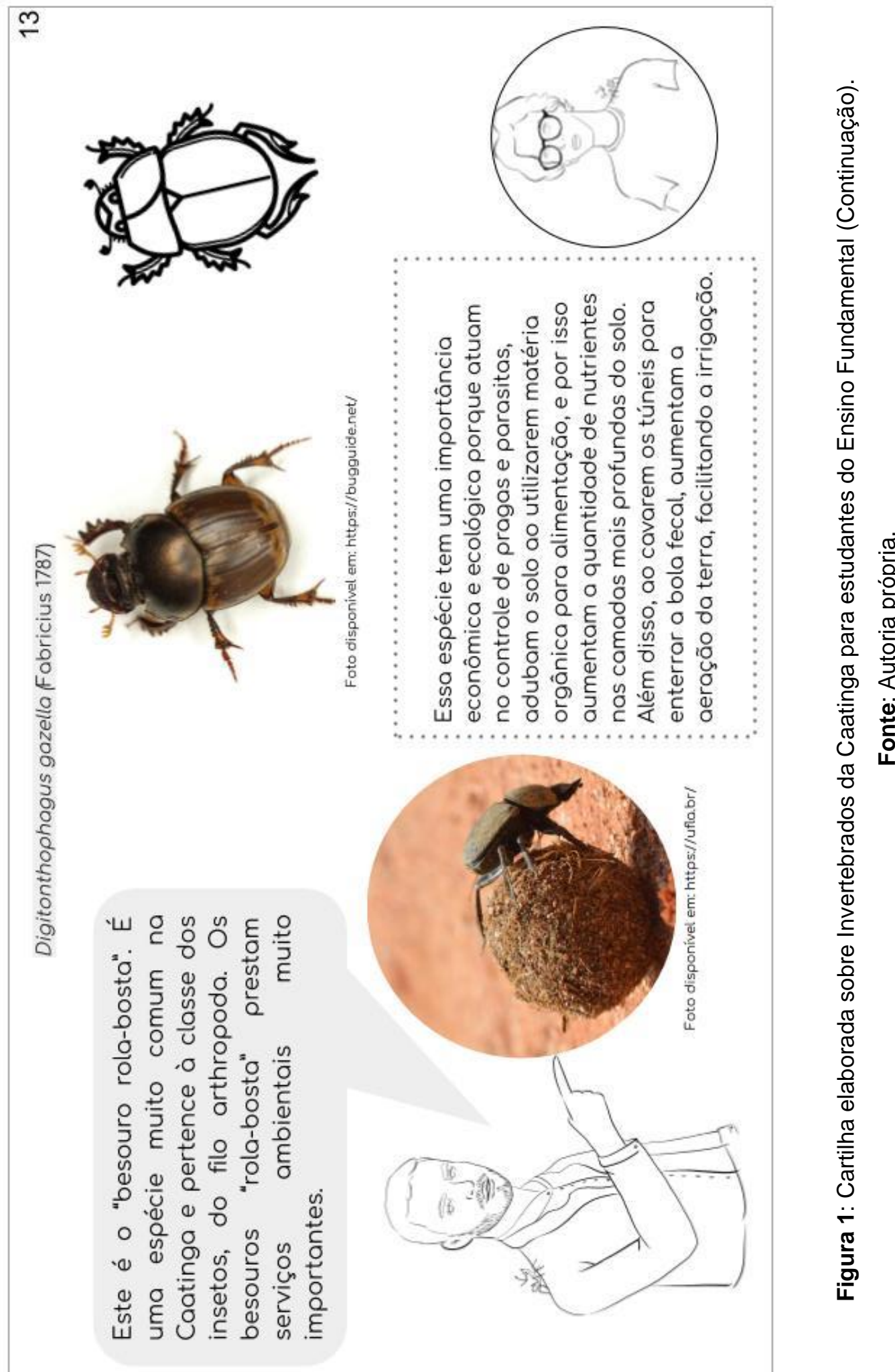

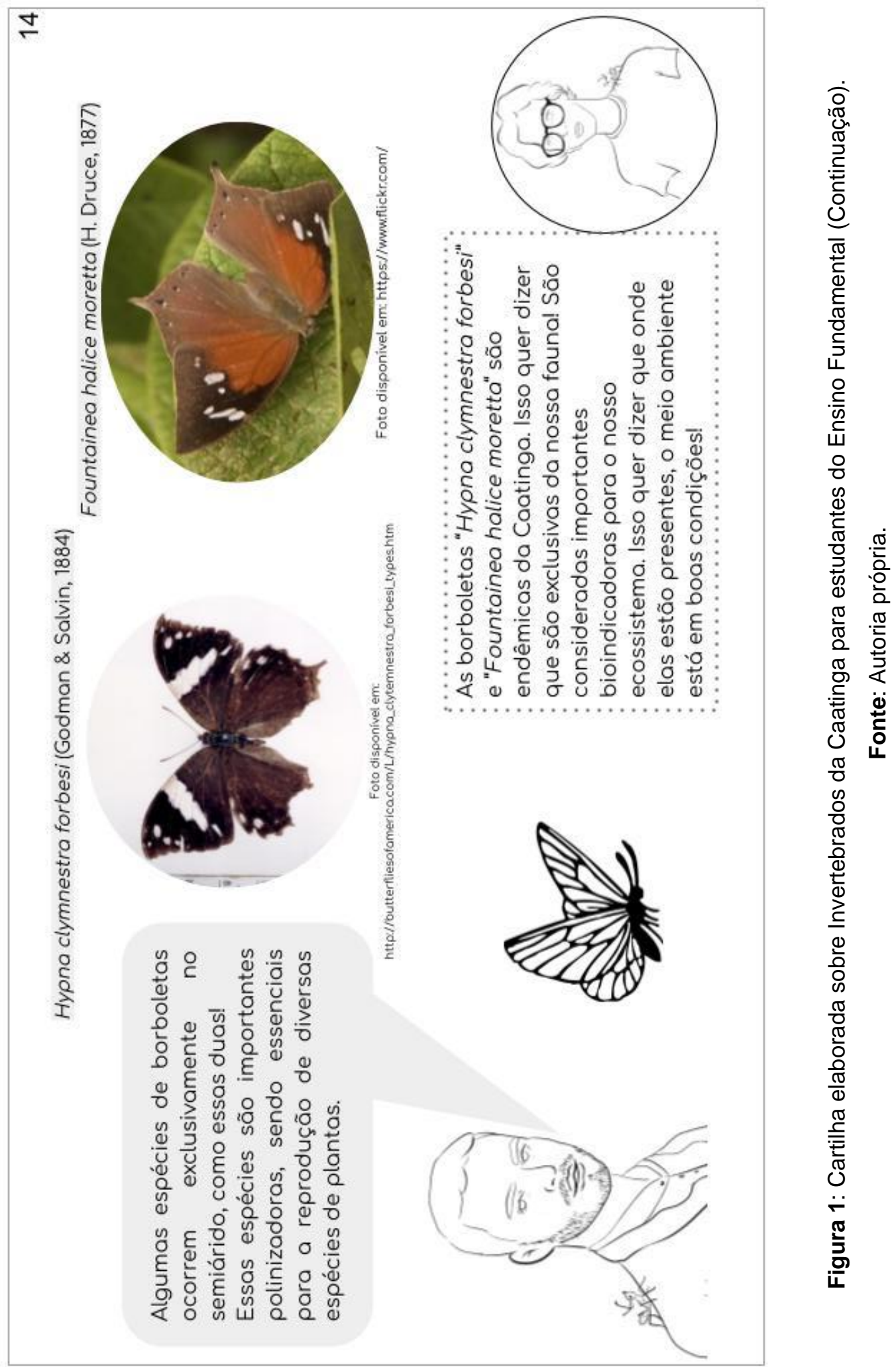

Revbea, São Paulo, V. 15, № 6: 17-51, 2020. 


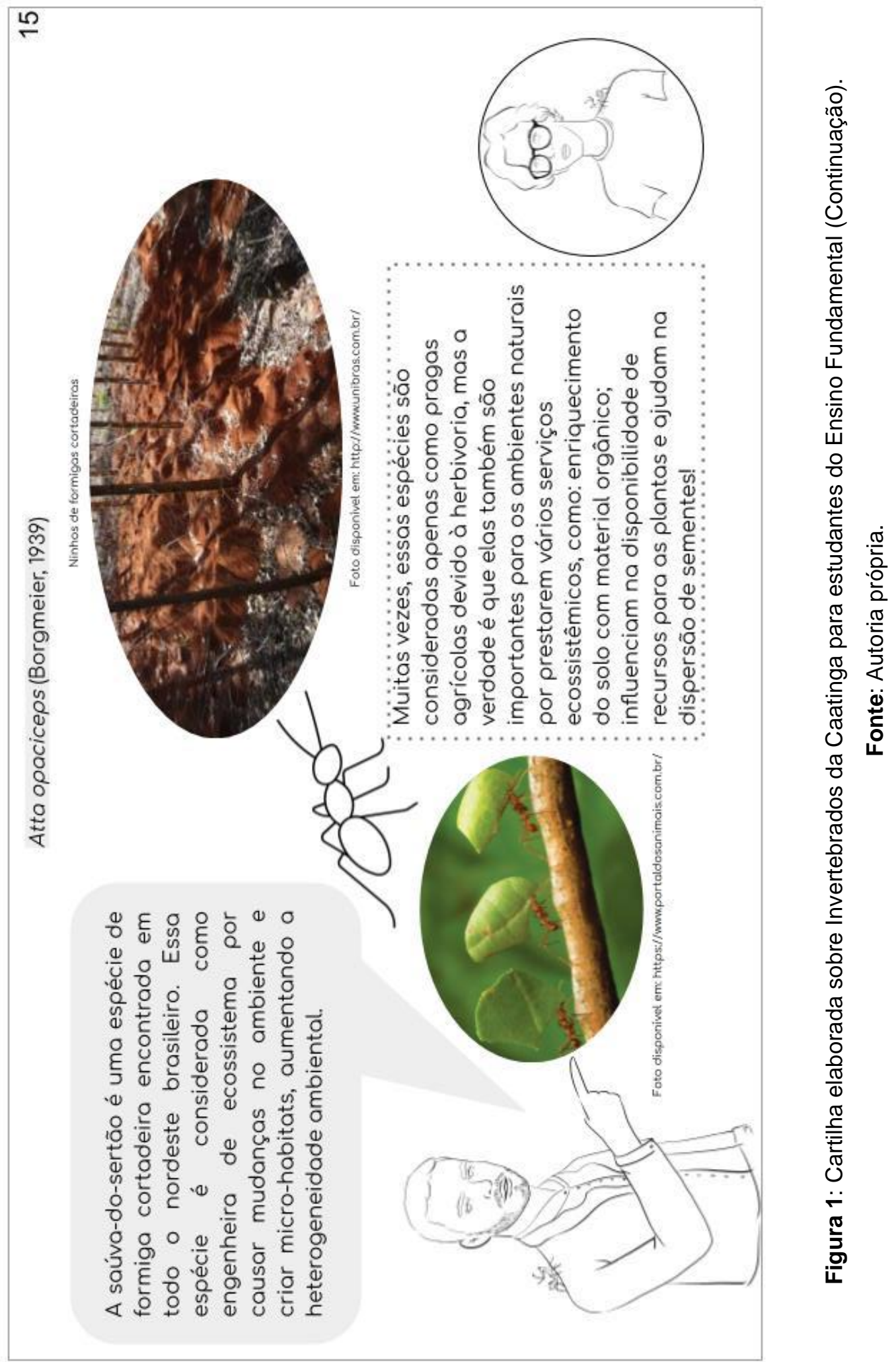



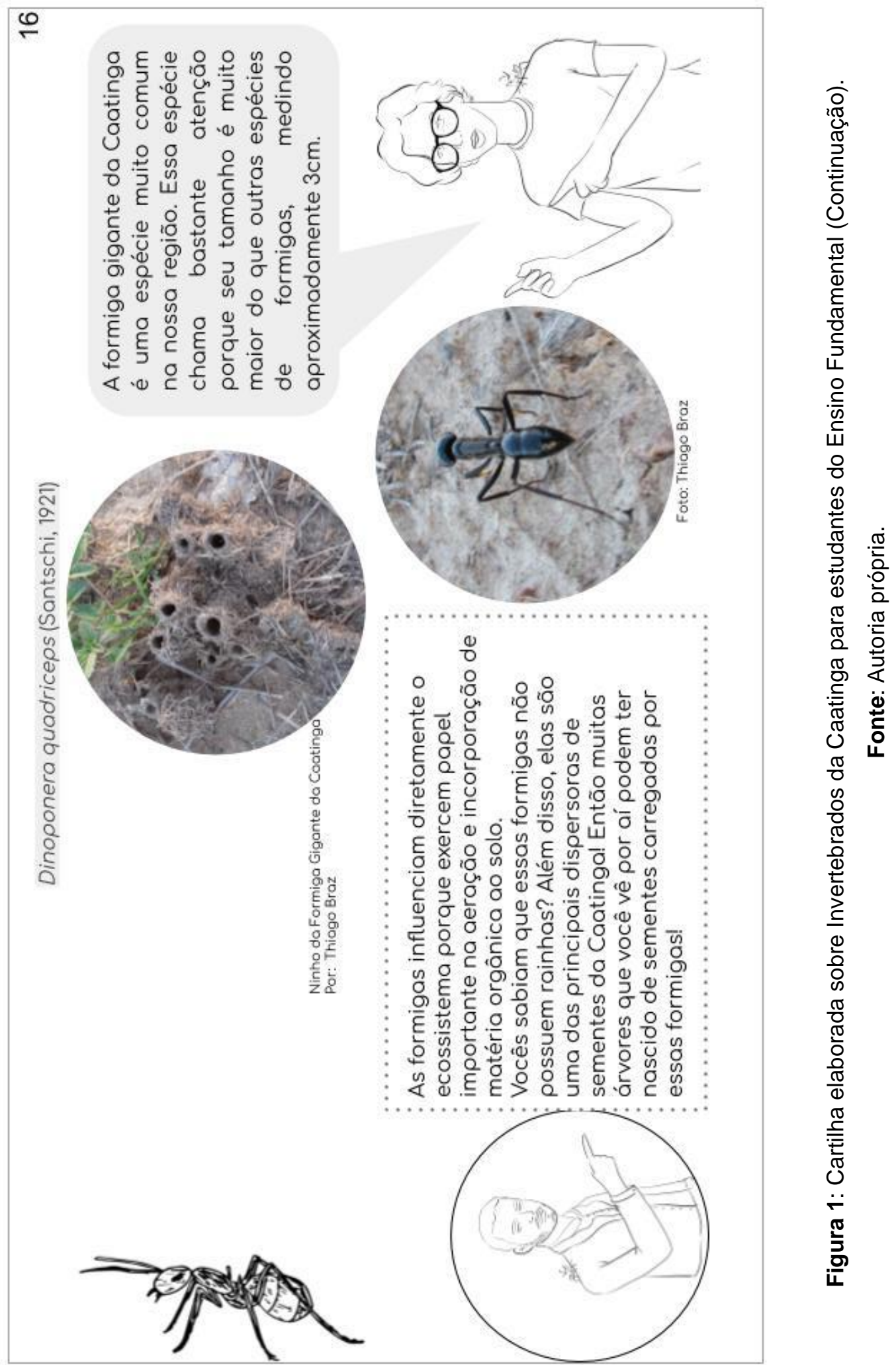

Revbea, São Paulo, V. 15, № 6: 17-51, 2020. 


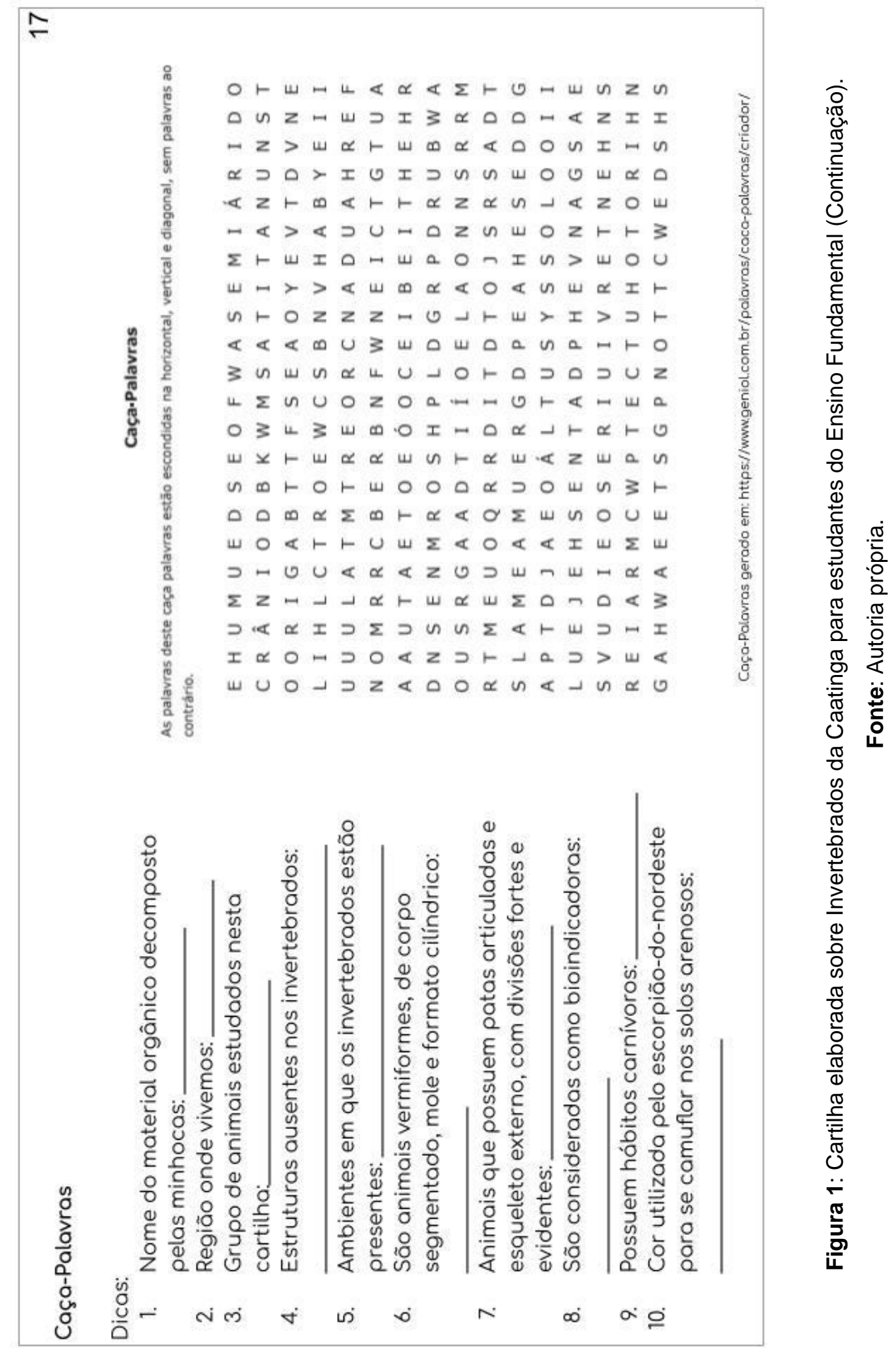

Revbea, São Paulo, V. 15, № 6: 17-51, 2020. 

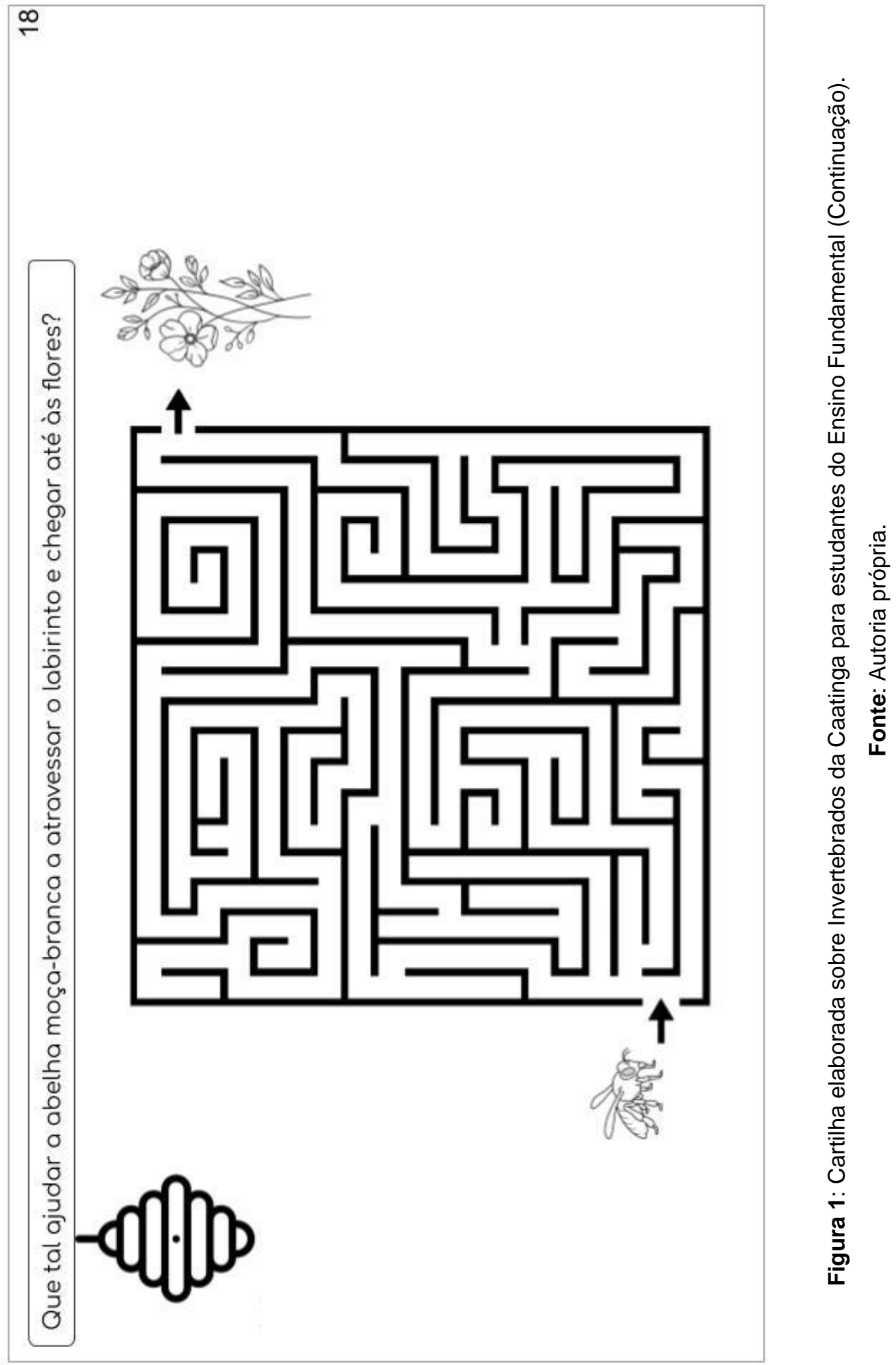

Revbea, São Paulo, V. 15, № 6: 17-51, 2020.

revista brasileira educação ambiental 

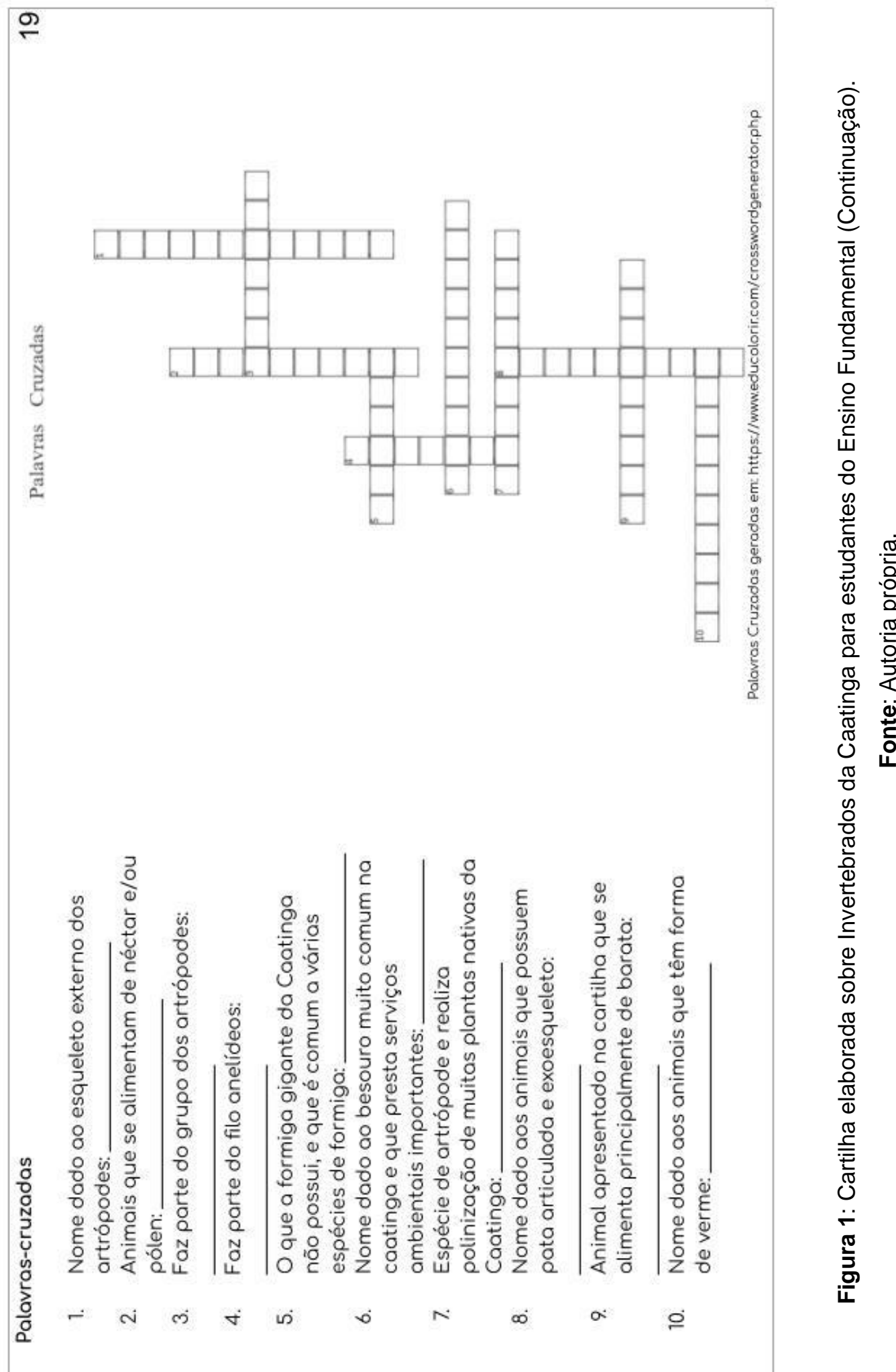

Revbea, São Paulo, V. 15, № 6: 17-51, 2020. 

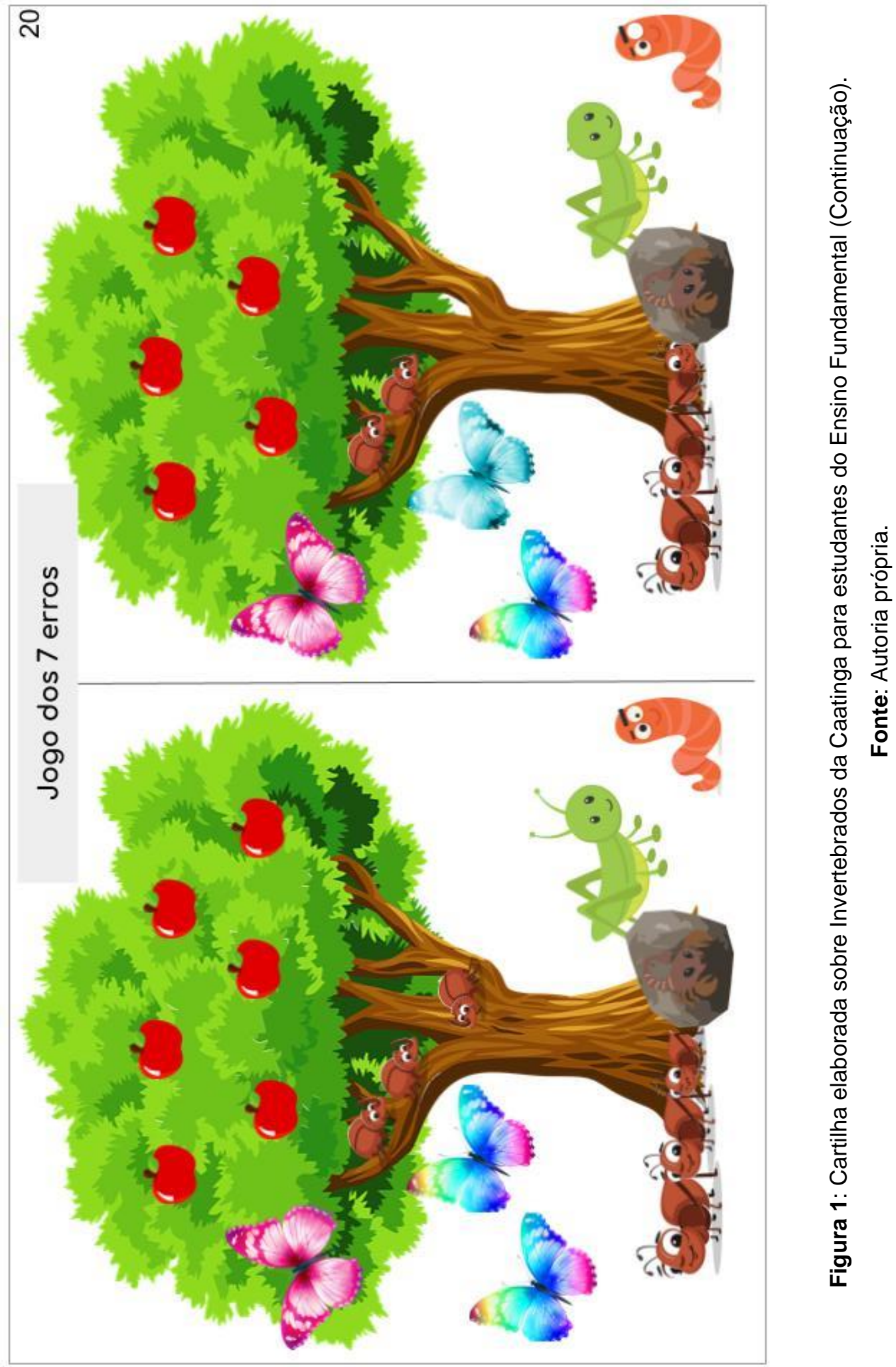

Revbea, São Paulo, V. 15, № 6: 17-51, 2020. 


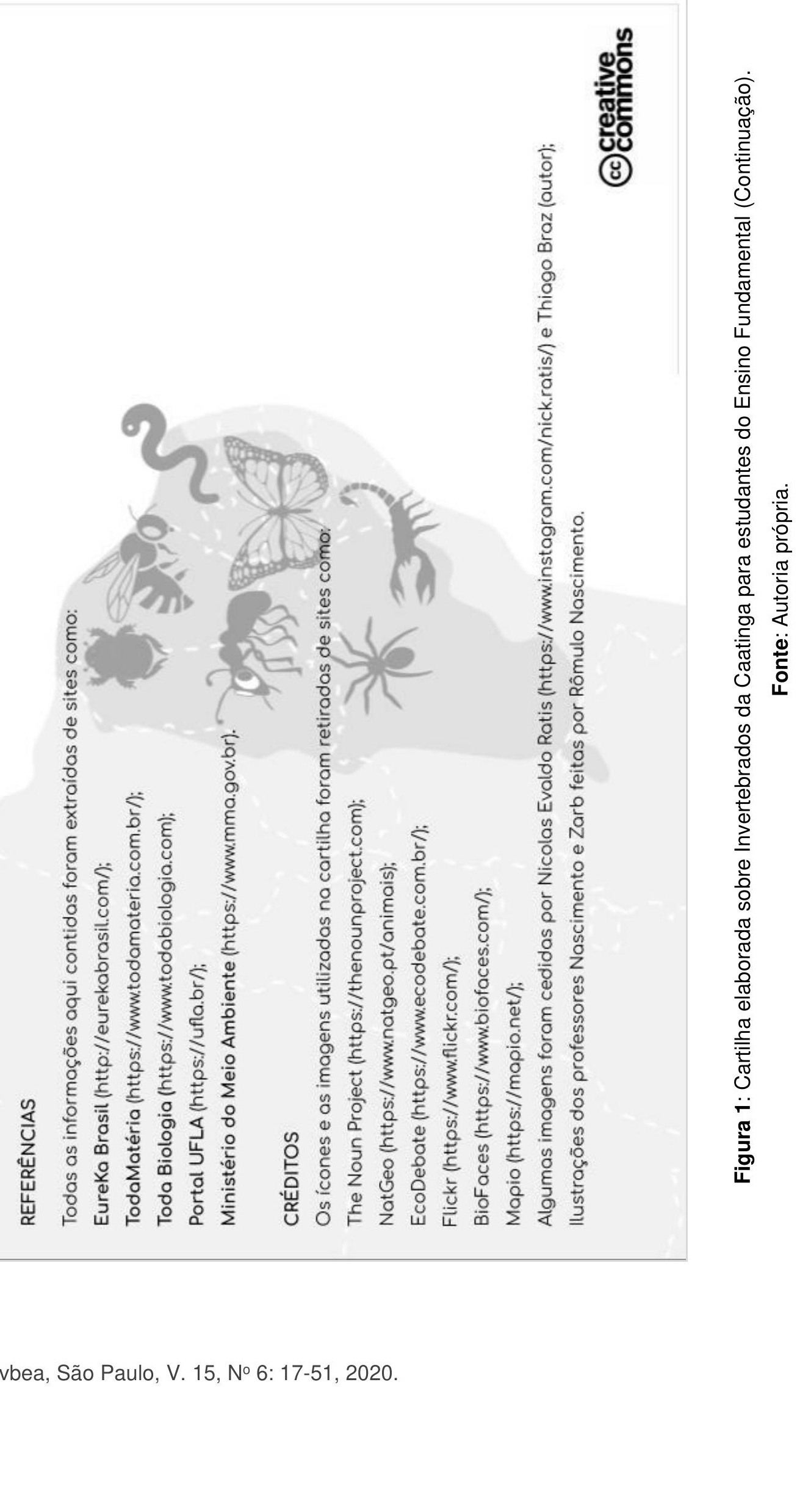


O uso de recursos pedagógicos como as cartilhas tem gerado resultados positivos. Isso é mostrado, por exemplo, no trabalho de Ramos et al. (2012) onde se utilizou uma cartilha contendo jogos pedagógicos e informações sobre animais peçonhentos em uma comunidade escolar, e foi concluído que os jogos educativos tiveram papel fundamental na reflexão e na troca de conhecimento entre os participantes, além de fornecer também informações sobre essas espécies, sua prevenção e orientações em casos de acidentes. De maneira similar, Araújo et al. (2018), ao produzirem uma cartilha abordando questões relacionadas a Educação Ambiental, ações antrópicas, desenvolvimento sustentável e animais peçonhentos, destacam a importância de ações educativas que almejam a construção de valores e conhecimentos que interfiram positivamente na sociedade.

Paralelamente, Diniz, Cordeiro Junior e Sabino (2016) aplicaram um questionário antes e após a utilização de uma cartilha sobre espécies da fauna do Cerrado nos 6 e $7^{\circ}$ anos de escolas públicas e, quando as respostas foram comparadas, observaram que houve um aumento no número de animais nativos citados pelos estudantes, concluindo que o material utilizado forneceu aos estudantes informações, interesse sobre o tema, conhecimento e valorização da fauna local. Azevedo e Almeida (2017) sugerem que ações de EA nos espaços escolares e o desenvolvimento de recursos didáticos como as cartilhas contribuem tanto na formação de cidadãos críticos e conscientes do seu papel social, quanto na formação de profissionais atuantes que valorizem o meio ambiente e sua importância para o desenvolvimento social.

Do mesmo modo, Braz et al. (2018) avaliaram o conhecimento de estudantes do $1^{\circ}$ ano do Ensino Fundamental de duas escolas a respeito de questões relacionadas às medidas de prevenção, contágio e sintomas em seres humanos e animais infectados por Leishmania spp. e assumiram que as atividades lúdicas presentes na cartilha, que foi distribuída durante a intervenção, foram fundamentais para a compreensão e fixação do conteúdo apresentado. Pinheiro et al. (2010) desenvolveram uma cartilha de EA com vistas à preservação dos manguezais e do caranguejo-uçá para disseminar informações sobre a importância desse ecossistema, bem como da fauna e da flora e destacaram que esse instrumento de informação pode promover discussões, informações e propiciar reflexões, sugerindo que práticas educacionais ligadas à EA promovem mudanças de comportamento e desenvolvimento de conhecimento individual.

Sousa e Do Carmo (2020) afirmam que o tema Meio Ambiente, muitas vezes, é abordado de forma superficial, e sugerem que as cartilhas educacionais podem explorar os problemas locais, tornando-se uma alternativa ao ensino tradicional, desde que o material permita ao aluno construir seus próprios conhecimentos, desenvolvendo seu senso crítico para atuar na sociedade e exigir políticas ambientais que garantam uma sociedade mais justa, considerando o desenvolvimento sustentável.

As cartilhas possuem a vantagem de serem utilizadas tanto nos espaços formais, quanto nos espaços informais de educação. Nesse sentido, 
Alves, Gutjahr e Pontes (2019) sugerem que as cartilhas, quando produzidas com linguagem acessível a todos os públicos, são ótimos instrumentos para a socialização do conhecimento científico. Entretanto, para confeccionar a cartilha, é necessário conhecimento do assunto ou do problema que será abordado e embasamento teórico, bem como criatividade na elaboração do material e formas estratégicas para inserir as informações, buscando alcançar o maior número de pessoas leigas e interessadas no problema que está sendo abordado (ALVES, GUTHJAHR, PONTES, 2019).

Prazeres e Aguiar (2020), em seus escritos, relatam a falta de materiais didáticos para estudo, aprofundamento e trabalho da temática ambiental com crianças, especialmente na educação infantil e sugerem a utilização de cartilhas como opções viáveis, uma vez que esse material estimula a criatividade, contribui e desperta nos alunos o interesse pelas questões ambientais. Dessa forma, as cartilhas têm ganhado cada vez mais espaço nos diferentes meios e com diferentes temáticas, e têm contribuído positivamente para promover discussões e reflexões sobre temáticas ambientais, sensibilizando crianças, adolescentes e adultos.

\section{Conclusão}

As cartilhas e outros recursos didáticos complementares têm ganhado cada vez mais espaço nas escolas, bem como em outros ambientes. Apesar disso, percebe-se que muito ainda precisa ser feito, principalmente no que diz respeito a materiais que valorizem os diferentes contextos regionais. Considerando os problemas nos livros didáticos relativos à baixa quantidade de informações sobre a biodiversidade da Caatinga, as cartilhas podem ser instrumentos eficientes para o conhecimento e valorização desse ecossistema, especialmente sobre os invertebrados, que ainda são pouco conhecidos tanto pelos cientistas quanto pela população.

Este trabalho pode contribuir para a disseminação dos conhecimentos biológicos e ecológicos sobre as espécies de invertebrados da Caatinga de forma lúdica e ilustrada, no Ensino Fundamental, não deixando de lado seu caráter científico e informativo. Além disso, pode instigar professores e alunos a agirem em prol desses animais, aumentando a valorização e consequente conservação dos mesmos.

Adicionalmente às contribuições para o ensino, conhecimento e valorização da fauna invertebrada da Caatinga, também poderá contribuir para a redução da degradação dos habitats desses animais e sua eliminação do ambiente, além de avançar nas metas do Objetivo do Desenvolvimento Sustentável 15, sobre a vida terrestre, que visam interromper o processo de perda de habitats e, consequentemente, da biodiversidade. 


\section{Agradecimentos}

Ao Programa de Pós-graduação em Ciência e Tecnologia Ambiental (PPGCTA) da Universidade de Pernambuco Campus Petrolina.

À Coordenação de Aperfeiçoamento de Pessoal de Nível Superior (CAPES), Brasil - Código de Financiamento 001.

À Fundação de Amparo à Ciência e Tecnologia do Estado de Pernambuco (FACEPE) pela concessão de bolsas e financiamento do projeto "Aprendendo sobre o valor da biodiversidade da Caatinga e seus serviços ecossistêmicos no ensino escolar" (FACEPE APQ - 0177-2.05/18).

\section{Referências}

ALVES, R.J.M.; GUTJAHR, A.L.N.; PONTES, A. N. Processo metodológico de elaboração de uma cartilha educativa socioambiental e suas possíveis aplicações na sociedade. Revista Brasileira de Educação Ambiental (RevBEA), v. 14, n. 2, p. 69-85, 2019.

ARAÚJO, C.C. et al. Elaboração de uma cartilha ilustrada como estratégia de educação ambiental para a preservação do meio ambiente e medidas que devem ser adotadas em caso de acidentes com animais peçonhentos. Revista Presença, v. 1, n. 13, p. 32, 2019.

BACELAR, B. M.F. et al. Metodologia para elaboração de cartilhas em projetos de Educação Ambiental em micro e pequenas empresas. SEBRAE, 3 p, 2009.

BARBOSA, G.S.; RAMOS, M.A. Conhecimento ecológico local e percepção ambiental de estudantes sobre o bioma caatinga e sua relação com 0 conhecimento científico. Experiências em Ensino de Ciências, v.15, n.1, 2020.

BARRAZA, L.B.; CUARÓN, A.D. How values in education affect children's environmental knowledge. Journal of Biology Education, v. 39, ed. 1, 2004.

BLACK, S.H.; SHEPARD, M.; ALLEN, M.M. Endangered invertebrates: The case for greater attention to invertebrate conservation. Endangered Species Update, v. 18, n. 2, p. 41-49, 2001.

BRASIL. Secretaria de Educação Média e Tecnológica. PCN + Ensino Médio: Orientações Educacionais Complementares aos Parâmetros Curriculares Nacionais. Vol. Ciências da natureza, matemática e suas tecnologias. Brasília: MEC/SEMTEC, 2002.

BRASIL. Lei no 9.795 de 27 de abril de 1999. Brasil. Disponível em: http://www.planalto.gov.br/ccivil 03/leis/19795.htm Acesso em: 08 out. 2020.

BRAZ, P. H. et al. Educação em saúde para alunos do primeiro ano do ensino fundamental sobre a leishmaniose em seres humanos e animais. Pubsaúde, v. 1, n. 1, p. 1-7, 2018. 
BURGESS, D.J.; MAYER-SMITH, J. Listening to Children: Perceptions of Nature. Secondary Education, v. 3, 2011.

CARVALHO, W.S.; SANTOS, L.R.S.; OLIVEIRA, S.F. OLIVEIRA, F.M.P.; ARNAN, X.; LEAL, I.R. Formigas como provedoras de serviços ecossistêmicos na Caatinga: Como informar a sociedade sobre pesquisas ecológicas. Journal of Environmental Analysis and Progress, v. 5, n. 3. p. 281-287, 2020.

DINIZ, F.M.; CORDEIRO JÚNIOR, D.A.; SABINO, C.V.S. Cartilha ilustrada com alguns animais nativos do cerrado: um material paradidático de ciências, para estudantes de escolas públicas de Esmeraldas - MG Revista da Universidade Vale do Rio Verde, v. 14, n. 2, p. 1242-1254, 2016.

DRISSNER, J.; MUNZ, S. Children and animals a comparison between the awareness of animal groups and the actual number of different species. Elk Asia Pacific Journal of Social Science, v. 6, n. 1, p. 32-35, 2019.

ESTEVE, P.; JAÉN, M.; BANOS-GONZÁLEZ, I. Changes in the level of relationship between invertebrates and society of pre-service primary school teachers, after an educational intervention. Journal of Biological Education, v. 00, n. 00, p. 1-16, 2019.

LEANDRO, C.; JAY-ROBERT, P. Perceptions and representations of animal diversity: Where did the insects go? Biological Conservation, v. 237, p. 400408, 2019.

MODRO, A.F.H.; COSTA, M.S.; MAIA, E.; ABURAYA, F.H. Percepção entomológica por docentes e discentes do município de Santa Cruz do Xingu, MT, Brasil. Biotemas, Florianópolis, v. 22, n. 2, p. 153-159, 2009.

PACIENCIA, G.P. et al. A utilização dos macroinvertebrados aquáticos de riachos do município de Vilhena - RO na confecção de cartilhas de Educação Ambiental. Revista Monografias Ambientais, v. 14, n. 1, p. 176 -182, 2015.

PEDRINI, A.G.; BROTTO, D.S.; LOPES, M.C.; FERREIRA, L.P.; LOPES, N.P.G. Percepções sobre meio ambiente e mar por interessados em ecoturismo marinho na área de proteção ambiental marinha de Armação de Búzios, estado do Rio de Janeiro, RJ, Brasil. Pesquisa em Educação Ambiental, v. 8, n. 2, p. 59-75, 2013.

PERNAMBUCO. Parâmetros para a Educação Básica do Estado de Pernambuco. Parâmetros Curriculares de Ciências Naturais - Ensino Fundamental. Pernambuco: Secretaria de Educação, 2013. Disponível em: http://www.educacao.pe.gov.br/portal/upload/galeria/7801/Conteudos de Cien cias Naturais EF.pdf. Acesso em: 08 out. 2020

PINHEIRO, M.A.A. et al. Educação ambiental sobre manguezais na baixada santista: uma experiência da UNESP/CLP. Revista Ciência em Extensão, v. 6, n. 1, p. 19-27, 2010. 
PRAZERES, L.G.C.; AGUIAR, D.C. O meio ambiente no meio do mundo: o fazer na educação infantil municipal em Macapá/Amapá. Brazilian Journal of Animal and Environmental Research, v. 3, n. 2, p. 168-178, 2018.

PROFICE, C. Nature as a living presence: Drawings by Tupinamba' and New York Children. PLoS ONE, v. 13, n. 10, 2018.

RAMOS, E.L.P. et al. Uma abordagem lúdica dos animais peçonhentos no ensino fundamental. Em Extensão, v. 11, n. 2, p. 45-53, 2012.

SÃO PAULO. Secretaria do Meio Ambiente do Estado de São Paulo (SMA/SP). Coordenadoria de Planejamento Ambiental Estratégico e Educação Ambiental. In: Educação Ambiental: vinte anos de políticas públicas. São Paulo, SMA/SP, 2003.

SILVA, T.C.; MEDEIROS, P.M.; ARAUJO, T.A.S.; ALBUQUERQUE, U.P. Northeastern Brazilian students' representations of Atlantic Forest fragments. Environment, Development and Sustainability, v. 12, n. 2, p. 195-211, 2010.

SILVA, T.C.; CHAVES, L.S.; ALBUQUERQUE, U.P. O que é percepção ambiental?. In: ALBUQUERQUE, U.P. Introdução à Etnobiologia. 2 ed. Recife, NUPEEA, 2018. p. 83-88.

SILVA, J.M.C.; LEAL, I.R.; TABARELLI, M. Caatinga: The Largest Tropical Dry Forest Region in South America. Springer, p. 577. 2017.

SILVA, T. C.; CAMPOS, L.Z.O.; SILVA, J.S.; SOUSA, R.S.; ALBUQUERQUE, U.P. Percepção e aproveitamento da biota. In: ALBUQUERQUE, U.P. Introdução à Etnobiologia. 2 ed. Recife, NUPEEA, 2018. p. 89-96.

SOUSA, S. G.; DO CARMO, J. A. Educação Ambiental E a Realidade Local: O Uso De Cartilha No Processo Ensino-Aprendizagem. Revista Equador, v. 9, n. 1, p. 133-153, 2019.

TRIGUEIRO, P. Especialistas debatem educação no semiárido. Folha de Pernambuco, Pernambuco, jun. 2017. Disponível em: http://folhape.com.br/noticias/noticias/cotidiano/2017/06/13/NWS,30941,70,449, NOTICIAS, 2190-ESPECIALISTAS-DEBATEM-EDUCACAO-SEMIARIDO.aspX Acesso em: 16 set. 2017.

TRINDADE, O.S.N.; SILVA JÚNIOR, J.C.; TEIXEIRA, P.M.M. Um estudo das representações sociais de estudantes do ensino médio sobre os insetos. Revista Ensaio, Belo Horizonte, v.14, n. 03, p. 37-50, 2012.

VIEIRA, V.; BIANCONI, M.L.; DIAS, M. Espaços não-formais de ensino e o currículo de ciências. Ciência e Cultura, n. 4, v. 57, p. 21-23, 2005.

VICENTE, J.P. Único bioma $100 \%$ brasileiro, Caatinga esconde riquezas naturais subestimadas. National Geographic. 2020. Disponível em: https://www.nationalgeographicbrasil.com/natgeo-

ilustra/caatinga\#: :text=Endêmica\%20da\%20Caatinga\%2C\%200\%20único,sub estimada\%20ao\%20longo\%20da\%20história. Acesso em: 14 de set. 2020. 